\title{
Estado nutricional e consumo alimentar entre estudantes dos cursos de nutrição e de letras: um estudo longitudinal
}

Renata Doratioto Albano

Tese apresentada ao Programa de Pós - Graduação em Saúde Pública da Faculdade de Saúde Pública da Universidade de São Paulo para obtenção do título de Doutor em Saúde Pública.

Área de Concentração: Nutrição

Orientadora: Prof. Dra. Ana Maria D. Gambardella 


$$
45947 / 2005 \text { doc }
$$

Autorizo, exclusivamente para fins acadêmicos e científicos, a reprodução total ou parcial desta tese, por processos fotocopiadores.

Assinatura:

Data: 


\section{DEDICATÓRIA}


Aos meus pais, Arlene e Paulo, que sempre me apoiaram e ajudaram nos momentos mais dificeis de minha vida profissional e pessoal;

Aos meus irmãos, Thiago e Daniel, às minhas cunhadas Eliana e Lúcia, e aos meus tios Dorival e Luzia pelo constante apoio; em especial ao Gustavo, meu irmão, e à Andreza, minha cunhada, pela carinhosa amizade e auxilio nos momentos mais dificeis;

A minha sobrinha Catarina e ao seu irmão Rodolfo, "meu sobrinho de coração", por me proporcionarem momentos tão alegres nos últimos anos;

Ao meu marido, amigo e companheiro "Doug", que apesar de todas as dificuldades que passamos juntos, nunca me deixou desistir;

A todos os alunos dos cursos de Nutrição e Letras, ingressantes em 2002, que aceitaram participar desta pesquisa, que sem eles não teria sido possivel a realização da mesma. 
AGRADECIMENTOS 
A Professora Dra. Ana Maria Dianezi Gambardella do Departamento de Nutrição da FSP/USP, pela orientação, carinho e dedicação em todas as etapas desta pesquisa;

Aos Professores Dráuzio Costa Pires de Campos, diretor do Centro da Educação e Luzana M. Bernardes, diretora do Centro de Ciências da Saúde, da Instituição Particular de Ensino Superior de Santos, pela permissão na realização da pesquisa;

As professoras Cláudia Ridel Juzwiak, do curso de Nutrição, Isabel Yamanaka e Elita Cezar Argemon, do curso de Letras por cederem parte de suas aulas para a coleta dos dados;

A Profa Dra. Ana Maria Cervato Mancuso do Departamento de Nutrição da FSP/USP, à profa Associada Sabina Lea Davidson Gotlied do Departamento de Epidemiologia da FSP/USP, à profa Adjunta Olga Maria Silvério Amâncio do Departamento de Pediatria da UNIFESP, à profa Dra. Denise Giácomo da Motta do Departamento de Nutriçáo da UNIMEP, à Profa Dra. Maria Cristina Faber Boog do Departamento de Enfermagem da UNICAMP, pelas excelentes sugestoes, contribuindo para a melhora da qualidade deste trabalho;

A Bibliotecária Maria Lúcia Evangelista de Faria Ferraz, da FSP/USP, pela atenção dispensada na correção das referências;

As alunas de Graduação do curso de Nutrição da Instituição Particular de Ensino Superior de Santos, Fernanda Vasquez e Luciana Ferreira, pelo auxílio na coleta dos dados;

As minhas colegas de trabalho Suemy, Mônica, Andréa, Sandra e Pilar, pelo apoio nos momentos mais dificeis;

As minhas amigas Solange, Luciana e Valdete pela carinhosa amizade $e$ apoio nos momentos mais dificeis;

A Sociedade Visconde de Sáo Leopoldo pela concessão da Bolsa de Capacitação Docente;

A Todos que direta e indiretamente colaboraram comigo na realização deste trabalho. 
ALBANO RD. Estado nutricional e consumo alimentar entre estudantes dos cursos de Nutrição e de Letras: um estudo longitudinal. São Paulo; 2004 [Tese de Doutorado - Fac. de Saúde Pública da Universidade de São Paulo].

Objetivo:O objetivo desse estudo foi verificar e comparar o estado nutricional e o consumo alimentar entre estudantes de dois cursos de áreas distintas (Nutrição e Letras) em uma Instituição Particular de Ensino Superior (IPES) ao longo de um ano. Casuistica e Métodos: Estudo do tipo longitudinal, realizado em 2003 e 2004 em uma IPES, localizada na cidade de Santos/SP. A população de estudo foi constituida de alunos matriculados nos $3^{\circ}$ e $5^{\circ}$ semestres, respectivamente, em 2003 e 2004, nos cursos de Nutrição e Letras. Foram analisados os valore do indice de massa corporal e de consumo alimentar, bem como hábitos alimentares e estilo de vida. Para a análise estatistica foram utilizados os softwares SPSS, versão 11.0 e o Statística, versão 5.5. Resultados: Detectou-se maior número de estudantes do curso de Letras com excesso de peso corporal, sendo $21,6 \%$ em 2003 e 15\% em 2004. Com base na média do registro alimentar de 3 dias dos estudantes, verificou-se desequilibrio no valor calórico total devido a maior quantidade de gordura. Para os micronutrientes, as médias de consumo de cálcio e ferro ficaram abaixo dos valores recomendados em ambos os periodos de estudo. As mudanças ocorridas entre 2003 e 2004 para os hábitos alimentares, estilo de vida, consumo médio dos macronutrientes em relação ao valor calórico total, cálcio, ferro, consumo de água e IMC médio intra os alunos dos curso (Nutrição $X$ Nutrição, Letras X Letras) e entre os alunos dos cursos (Nutrição X Letras) nos periodos de 2003 e 2004 não foram estatisticamente significativas. Considerações finais: Em 2003, os alunos dos cursos apresentaram-se de maneira semelhante, com exceção do estado nutricional, média de IMC e da idade. Em 2004, os alunos de ambos os cursos comportaram-se também de maneira semelhante, com exceção do estado nutricional, onde houve número maior de alunos com excesso de peso no curso de Letras. As mudanças analisadas nos hábitos alimentares, estilo de vida, consumo alimentar, indice de massa corporal, intra os alunos dos cursos e entre os alunos dos cursos nos periodos estudados não foram estatisticamente significativas.

Descritores: universitários, estado nutricional, avaliação antropométrica, indice de massa corporal, consumo alimentar. 
ALBANO RD. Nutritional status and food intake of students attending Nutrition and Language \& Literature courses: a longitudinal study São Paulo (BR); 2004 [Tese de Doutorado - Fac. de Saúde Pública da USP].

Objective: The objective of this study was to verify and compare the nutritional status and the food intake of students attending courses from distinctive areas (Nutrition and Languages \& Literature) in a Private Institution of Superior Education (PISE) throughout a year. Casuistic and Methods: Longitudinal study conducted during 2003 and 2004 in a PISE located in the city of Santos/SP. The study population consisted of students registered in the 3rd and 5th semesters, respectively, in 2003 and 2004, in the Nutrition and Languages \& Literature courses. The analyzed values were the body mass index and the food intake, as well as the food habits and life style. For the statistical analysis the softwares SPSS, version 11.0 and Statistica, version 5.5 were used. Results: A greater number of Languages \& Literature students were detected as being overweight, being $21.6 \%$ in 2003 and $15 \%$ in 2004 . Based on the mean values of the 3-day food record, an unbalance in the total energy value was verified due to the greater amount of fat intake. For the micronutrients, the mean intake of calcium and iron were below the recommended values in both periods of the study. Changes which occurred during 2003 and 2004 in food habits, life style, mean intake of macronutrients in relation to the total energy intake, calcium, iron, water intake, and mean BMI inter students (Nutrition X Nutrition, Language \& Literature $X$ Language \& Literature) and between students (Nutrition X Language \& Literature) in the periods of 2003 and 2004 were not statistically significant. Final considerations: In 2003, the students of both courses presented themselves in a similar manner, with the exception of the nutritional status, mean BMI and age. In 2004 , students from both courses also behaved in a similar manner, with the exception of the nutritional status, when a greater number of overweight was observed in the Language 8 Literature course. The analyzed changes in the food habits, life style, food intake, BMI inter students and between courses in the studied periods were not statistically significant.

Descriptors: college students, nutritional status, anthropometric evaluation, body mass index, food intake. 


\section{$\begin{array}{llllll}\mathbf{I} & \mathbf{N} & \mathbf{D} & \mathbf{I} & \mathbf{C} & \mathbf{E}\end{array}$}

\section{INTRODUÇÃO}

1.1 Avaliação do estado nutricional.................................... 01

1.2 Aspectos demográficos da população jovem no mundo e 04 no Brasil

1.3 A Situação nutricional de estudantes universitários e dos 06 que freqüentam o curso de Nutrição.

1.4 O nutricionista como educador/orientador em saúde

\section{OBJETIVOS}

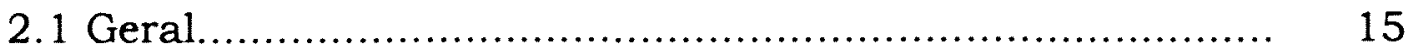

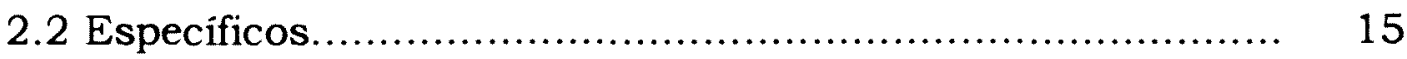

\section{CASUÍstica E MÉTOdOS}

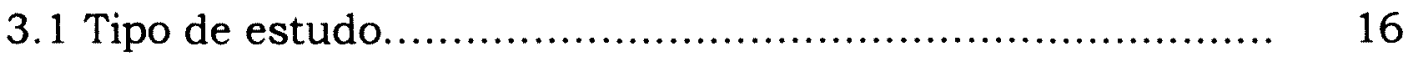

3.2 Local de estudo........................................................ 16

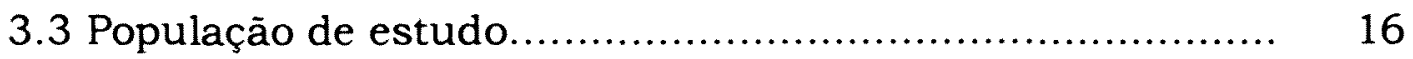

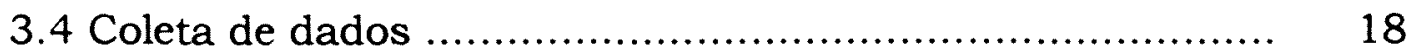

3.5 Variáveis de estudo................................................. 18

3.6 Análise estatistica.................................................. 23

3.7 Questões éticas.................................................... 25

\section{RESULTADOS}

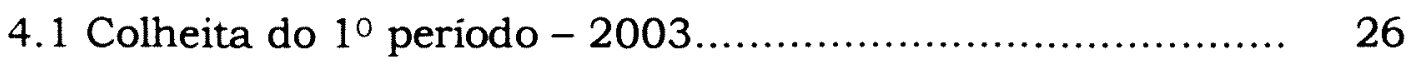

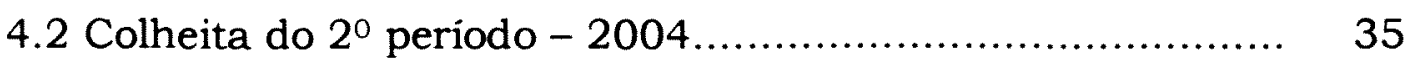

4.3 Mudanças de hábitos alimentares e de estilo de vida dos alunos dos cursos de Nutrição e Letras considerando as avaliações em 2003 e 2004.

4.4 Mudanças do consumo alimentar e do indice de massa corporal dos alunos dos cursos de Nutrição e Letras considerando as avaliações em 2003 e 2004 
4.5 Alimentos/preparações mais consumidos pelos alunos dos cursos de Nutrição e Letras

\section{DISCUSSÃO}

5.1 Características gerais, hábitos alimentares e estilo de vida 58

5.2 Estado nutricional............................................... 60

5.3 Consumo alimentar............................................... 65

6. CONSIDERAÇÕES FINAIS............................................ 76

7. REFERÊNCIAS ................................................ 78

\section{ANEXos}

Anexo 1 - Questionário - Características Gerais e Hábitos Alimentares.............................................................. I

Anexo 2 - Formulários para os dados de peso e estatura........ II

Anexo 3 - Instruções para o preenchimento do Registro Alimentar................................................................ III

Anexo 4 - Registro Alimentar de 3 Dias.............................. IV

Anexo 5 - Aprovação do Projeto pelo Comitê de Ética (COEP/FSP/USP) ....................................................... V

Anexo 6- Termo de Consentimento Livre e Esclarecido.......... VI

Anexo 7 - Relato dos alunos do Curso de Letras.................... VII

Anexo 8- Relato dos alunos do Curso de Nutrição.................. VIII 
1. INTRODUÇĀO 


\subsection{Avaliação do estado nutricional}

A maioria dos estudos realizados para a avaliação do estado nutricional de populações e grupos populacionais utilizam principalmente dados sobre consumo alimentar, antropométricos e de composição corporal, por serem métodos rápidos, de menor custo, quando comparados com outros métodos (por exemplo métodos bioquímicos), além de fornecer importantes informações nutricionais.

O estado nutricional de um individuo ou grupo de individuos é o resultado entre o consumo alimentar e as necessidades nutricionais, para permitir a utilização dos nutrientes, manter as reservas orgânicas e compensar as perdas. Do ponto de vista da promoção de saúde e prevenção de doenças, è de fundamental importância a avaliação nutricional dos diversos grupos populacionais, crianças, adolescentes, adultos, idosos e gestantes, com o objetivo principal de conhecer os problemas nutricionais para elaborar e aplicar medidas de intervenção (VERDU e GONZÁLEZ 1995).

Existem diversos métodos de avaliação do estado nutricional, podendo ser divididos em 4 grandes grupos:

a) avaliação do consumo alimentar;

b) avaliação antropométrica e da composição corporal;

c) avaliação bioquímica;

d) avaliação clínica (GIBSON 1990, VERDÜ e GONZÁLEZ 1995, DEHOOG 1998).

\subsubsection{Avaliaçào do consumo alimentar}

O conhecimento do consumo de alimentos, bem como, da quantidade de calorias e nutrientes ingeridos, em nivel individual e 
populacional, é importante para avaliar o estado nutricional e propor intervenções adequadas, bem como estudar as inter-relações do estado de saúde da população (MAJEM 1995).

Nos anos 70/80, houve aumento do interesse em aprofundar os estudos sobre a importância da dieta para a saúde de grupos populacionais específicos, tendo como objetivo primordial verificar a relação entre o consumo alimentar e a presença de determinadas doenças (MENCHÚ 1992).

Independentemente da meta final do estudo sobre o consumo alimentar, na maior parte da vezes, o objetivo intrinseco consiste em estimar quantitativamente o consumo dos alimentos, grupos de alimentos e nutrientes, durante um determinado periodo de tempo, caracterizando-se dessa forma os padrōes dietéticos e classificandoos quanto à ingestão adequada ou inadequada de alimentos e/ou nutrientes (LOPEZ 1995).

Vários métodos podem ser empregados para avaliar o consumo alimentar, cada um com suas vantagens e desvantagens, sendo os principais: recordatório de 24 horas: o individuo relata todos os alimentos e/ou preparações e bebidas consumidos no dia anterior da entrevista ou nas últimas 24 horas; registro alimentar: esse método consiste em anotar em formulário próprio todos os alimentos e/ou preparações consumidos ao longo do dia pelo individuo. Deve apresentar descrições detalhadas sobre os tipos e quantidades dos alimentos $\mathrm{e}$ bebidas consumidos durante um determinado periodo de tempo; questionário de freqüência alimentar: consiste em uma lista de alimentos elaborada especificamente para um determinado estudo onde $o$ individuo assinala a freqüência de consumo (diária, semanal, mensal...) de cada um deles. A informação requerida pode ser qualitativa, 
quantitativa, ou semi- quantitativa. Nesses 2 últimos casos 0 entrevistado assinala não somente a freqüência, mas também a quantidade consumida; história dietética: esse método consiste de uma extensa entrevista com o objetivo de se obterem informações sobre os hábitos alimentares atuais e do passado, incluindo um ou mais recordatórios de 24 horas e um questionário de freque ência alimentar (MAJEM 1995, WILLET 1998).

Dentre os métodos citados ressalta-se que todos apresentam apresentam pontos positivos e negativos (LOPEZ 1995). Entretanto, para a seleção do método, devem ser considerados alguns critérios: objetivo e tipo do estudo, caracteristicas demográficas da população e recursos materiais, humanos e econômicos (MAJEM 1995).

\subsubsection{Avaliação antropométrica}

As variáveis antropométrica, particularmente, o peso e a altura, são as principais medidas da avaliação do estado nutricional utilizadas em estudos populacionais, devido principalmente à simplicidade e à facilidade na obtenção dos dados (WILLETT 1998).

Estudos realizados em diversos grupos etários podem utilizar medidas de peso e altura para a avaliar o estado nutricional, em adultos, assim como podem avaliar a deficiência energético-protéica em crianças.

A combinação de medidas antropométricas oferece determinados indices antropométricos, peso/altura, altura/idade, peso/idade, utilizados para avaliar o crescimento em crianças e adolescentes, tomando-se seus valores como indicadores. Um indicador amplamente utilizado, para adultos e adolescentes, é o 
Indice de Quetelet, também chamado de Índice de Massa Corporal (IMC), obtido pela razão do peso corporal, expresso em quilogramas, e pela altura, em metros, elevada ao quadrado. (WILLETT 1998).

Para classificar o estado nutricional a partir do IMC, comparase o valor obtido com valores de referência, sendo utilizados geralmente para a população brasileira os valores de referência preconizados pela OMS (1995).

Estudos de avaliação nutricional têm sido realizados em diversos grupos populacionais, crianças, adolescentes, adultos, idosos. Porém é escassa a literatura nacional e internacional sobre o assunto em adolescentes e jovens universitários. Sabe-se, entretanto, que a prevalência de obesidade nos diversos grupos etários vem aumentando, não somente nos países desenvolvidos, mas também nos paises em desenvolvimento, tornando-se um sério problema de saúde pública, inclusive no Brasil (MONTEIRO e col. 2000).

\subsection{Aspectos demográficos da população jovem no mundo e no} Brasil

Desde as últimas décadas do século XIX, a população jovem (15-24 anos) no Brasil chegava a representar $31,8 \%$ da população total. Com a entrada dos imigrantes europeus, a população jovem (15-19 anos) registrou uma taxa de crescimento de 2,9\% a.a., entre 1890-1900, enquanto que a população total crescia a 1,9\% a.a., refletindo a imigração desse grupo etário (BAENINGER 1999).

Nos primeiros 20 anos do século $\mathrm{XX}$, houve uma taxa de crescimento da população brasileira de $2,9 \%$ a.a., enquanto a população de 15 a 19 anos, crescia a 4,2\% a.a., em função dos 
próprios efeitos diretos e indiretos da migração estrangeira, quando este grupo chegou a responder por $13,8 \%$ da população total, em 1920. Entre 1920 e 1940, no grupo etário de 15 a 19 anos, houve um decréscimo de $0,26 \%$ a.a., em virtude principalmente da menor entrada de estrangeiros subsidiados e do forte movimento de emigração. A população de 20 a 24 anos registrou considerável elevaçāo em seu ritmo de crescimento, do periodo de 1900-1920 para 1920-1940 (de 1,6\% a.a. para 2,9\% a.a., respectivamente), resultante da forte imigração familiar ocorrida no final do século XIX e início do $X X$, além da alta fecundidade assistida nesta etapa. Nos anos 50 , a população de 15 a 24 anos registrou uma taxa de crescimento de 2,5\% a.a.e nos anos 60, 3,6\% a.a. (BAENINGER 1999).

Segundo Bercovich e Madeira (1990), apesar das mulheres brasilleiras nascidas nas décadas de 1950 e 1960 terem apresentado niveis de fecundidade muito mais baixos do que as suas mães, a população jovem ainda continuará crescendo por um tempo expressivo. Esse crescimento populacional residual é chamado de inércia demográfica, e é um dos determinantes das ondas jovens que se observaram entre as décadas de 1980 e 1990, com profundos efeitos sociais e demográficos (CAMARANO e col. 2003)

De acordo com dados da Fundação IBGE, último Censo Demográfico (2000), do total da população brasileira (169.799.170 milhões), $10,56 \%$ corresponde a indivíduos na faixa etária entre $15 \mathrm{e}$ 19 anos. Para a faixa etária de 20 a 24 anos, a proporção correspondente é de $9,5 \%$ da população total brasileira (MINISTÉRIO DA SAÜDE 2001).

No caso específico da região Sudeste, segundo o Censo Demográfico (2000), do total da população residente na região (72.412.411 milhões), 9,88\% corresponde ao grupo etário entre 15 e 
19 anos, e 9,42\% ao grupo etário entre 20 e 24 anos (MINISTÉRIO DA SAÜDE 2001).

Embora houve discreta diminuição da proporção da população jovem brasileira entre os anos de 1980 e 2000, neste último ano, 38\% da população jovem encontrava-se na região Sudeste (CAMARANO e col. s.d.).

\subsection{Situação nutricional de estudantes universitários e dos que frequientam o curso de nutrição}

De acordo com estatísticas fornecidas pelo Ministério da Educação e Cultura (MEC) o ensino superior brasileiro apresentava, em 1998, aproximadamente 1,7 milhões de alunos, sendo $58 \%$ matriculados em instituições particulares e o restante em estabelecimentos püblicos (CATANI, 1998).

Dados do MEC/Instituto Nacional de Estudos e Pesquisas Educacionais Anisio Teixeira (INEP) (2002) mostraram que havia 1637 instituições de ensino superior, sendo 1442 (88,09\%) particulares e o restante instituições públicas. Dos 14399 cursos oferecidos, $9147(63,52 \%)$ são oferecidos pelas instituições privadas.

Segundo estatisticas do MEC/INEP, ingressaram em 2002 mais de 1,2 milhões alunos no ensino superior, sendo $76,72 \%$ em instituições particulares de ensino superior (MEC/INEP 2002).

Do total de matriculas realizadas em 2002, 56,5\% eram do sexo feminino, e 57,6\% do turno noturno (MEC/INEP 2002). 
Vários estudos mostram que estudantes universitários apresentam inadequado consumo alimentar e estado nutricional, inclusive graduandos de curso de nutrição.

OLIVARES e col. (1981), com o objetivo de verificar conhecimentos sobre alimentação e nutrição (consumo de alimentos, necessidades nutricionais, doenças nutricionais na coletividade, higiene dos alimentos, gestação e amamentação), realizaram estudo na Universidade do Chile com 1050 ingressantes, entre 17 e 21 anos, pertencentes às áreas de Biologia, Exatas e Humanas. Os resultados mostraram que somente $17 \%$ dos estudantes acertaram mais do que $50 \%$ das questões, sendo que os estudantes da área de Biológicas tiveram um melhor desempenho.

HERTZLER e col. (1995) desenvolveram um estudo com 416 estudantes (18 a 24 anos) do primeiro semestre do curso de nutrição com o objetivo de avaliar o consumo de gordura. Os resultados mostraram que o consumo médio foi de $30 \%$ de gordura em relação ao total de calorias; porém muitos estudantes apresentaram elevados consumos absoluto e relativo.

TAM e col. (1996), com o objetivo de comparar as diferença existentes entre os sexos masculino e feminino, no consumo de alguns nutrientes, balanço energético, atividade fisica e dieta com caracteristicas aterogênicas, realizaram um estudo com 122 estudantes do curso de nutrição de uma universidade na Califórnia, e concluiram que o elevado consumo de gorduras, colesterol, açúcar e o baixo consumo de fibras para o sexo masculino, quando comparado com o sexo feminino, indicava um risco maior para doenças cardiovasculares para os homens. 
SCHUETTE e col. (1999) desenvolveram uma pesquisa com 2489 estudantes de graduação de diversas áreas da saúde, incluindo o curso de Nutrição, em uma Universidade Mexicana. Foi constatado que apesar das médias de consumo dos 5 nutrientes avaliados (ferro, cálcio, magnésio, vitaminas $\mathrm{A}$ e $\mathrm{B}_{6}$ ) terem sido adequadas, $38 \% \mathrm{e}$ $31 \%$ dos estudantes consumiram menos do que o minimo recomendado em relação ao número de porções diárias de frutas e hortaliças, respectivamente.

Os resultados de uma pesquisa conduzida por FREGAPANE e ASENSIO-GARCIA (2000), com 205 estudantes de química com média de 24,8 anos de idade, de uma universidade espanhola, mostraram que o consumo de cereais e leguminosas foi inferior ao número de porções recomendadas; enquanto que o de ovos, carnes e embutidos (especialmente a salsicha) foi superior ao recomendado. Constataram também consumo de carboidratos em relação ao valor calórico total menor que 55\%. Noventa por cento dos participantes do estudo consumiram açúcar acima de $10 \%$ do total de energia e $95 \%$ mostraram um consumo excessivo no total de lipidios, sendo alto o consumo de colesterol. Quinze por cento dos individuos não alcançaram a recomendação para vitamina $\mathrm{D}$ e cálcio.

SORIANO e col. (2000) conduziram um pesquisa com 918 estudantes de graduação de uma universidade na Espanha. Verificaram que as médias de consumo de energia e magnésio para o sexo masculino e de energia, ferro, magnésio e zinco para o sexo feminino ficaram abaixo das recomendações preconizadas para a população espanhola. Concluíram que essa população universitária consumiu uma dieta com grande quantidade de proteinas e gorduras quando comparada com as recomendações para a população espanhola. 
Pesquisa conduzida por FIATES e col. (2001), em Santa Catarina, com 96 estudantes de graduação da área de Ciências da Saúde (CCS) e da área de tecnologia (CTC), com o objetivo de identificar e comparar hábitos alimentares e estilo de vida entre universitários de diferentes áreas, permitiu observar que os estudantes das 2 áreas em questão mostraram resultados muito semelhantes no consumo de carnes, frutas, gorduras, fibras, café e álcool, concluindo que a área de conhecimento não influenciou de forma determinante nos hábitos alimentares e estilo de vida dos estudantes.

Fujimori e col. (1986) relataram que, no Brasil, pouco se sabe sobre o hábito alimentar de estudantes, provavelmente em função dos universitários não constituírem, primordialmente, um grupo vulnerável a deficiências nutricionais (QUAIOTI e col. 1999).

Pesquisa realizada por RONCADA e col. (1990), com 50 alunos veteranos e 29 ingressantes de curso de nutrição em uma universidade pública, em São Paulo, verificou que, no desjejum, os veteranos apresentaram maior proporção no consumo de pão, laticinios, frutas, ovo, e derivados de carnes e menor percentual para bebidas estimulantes. Quanto ao jantar, as diferenças mais acentuadas foram em relação ao grupo das frutas, onde a freqüência do consumo pelos veteranos foi de $43 \%$ superior a dos ingressantes $\mathrm{e}$ no grupo das hortaliças, $21 \%$ superior, também entre os veteranos. Em uma outra parte do mesmo estudo, verificou-se que quando os alunos eram perguntados sobre os 5 alimentos que eles incluiam habitualmente em suas refeições, coincidentemente, o grupo de veteranos e o de ingressantes responderam, na mesma ordem, frutas, hortaliças, arroz, carne e leite; porém, enquanto os veteranos apontavam razões científicas, entre os ingressantes, predominavam razões de preferência e hábitos pessoais. As respostas sobre 5 
alimentos que procuravam excluir do cardápio mostraram conjunto reduzido de alimentos referidos pelos ingressantes, encabeçado por doces, gorduras, refrigerantes, carne de porco e massas, justificando que esses alimentos "engordavam" ou "faziam mal"; já os veteranos citaram relação maior de alimentos, embora os mais apontados quase se superpunham aos citados pelos ingressantes, com razōes técnicas, como elevação dos niveis de colesterol, calorias vazias ou presença de aditivos. Questão proposta apenas aos veteranos, sobre a influência dos conhecimentos de nutrição em sua alimentação, trouxe resultados como "refeições bem equilibradas", "maior sugestão de frutas e hortaliças", "substituição de alimentos industrializados por naturais" e "diminuição no uso de frituras", entre os mais citados, mostrando que os conhecimentos adquiridos no curso estão se traduzindo em prática pessoal.

Um outro aspecto dessa última pesquisa citada mostrou que a mãe era o elemento fundamental na seleção dos alimentos consumidos pela família dos alunos, nos 2 grupos (veteranos e ingressantes). Por outro lado, o fator que motivava essa escolha estava condicionado, por ordem decrescente, à preferência pessoal dos membros da familia, ao valor nutricional dos alimentos, ao custo e à facilidade de preparo, em ambos os grupos. Em relação aos modismos alimentares, verificou-se que apenas $4 \%$ dos veteranos aderiram a eles, elegendo o naturalismo. A questão referente a dietas especiais mostrou que $21 \%$ dos ingressantes e $14 \%$ dos veteranos delas faziam uso, principalmente visando o emagrecimento, informando terem reduzido o consumo de alimentos energéticos e aumentado o de alimentos ricos em fibras alimentares.

Estudo realizado por QUAIOTI e col. (1999), com 100 alunos do $2^{\circ}$ e $8^{0}$ semestre do curso de nutrição, em uma Universidade particular, em Bauru, por meio de um Questionário de Freqüência 
Alimentar (111 alimentos dispostos em grupos como na pirâmide alimentar, assinalando dentro de cada grupo o consumo semanal) mostrou que alunos de ambos semestres realizavam as 3 principais refeições (café da manhã, almoço e jantar) e um lanche durante os dias da semana e no final da semana apresentaram um outro tipo de distribuição de refeições: substituiam o almoço e o jantar por lanches. Em relação ao consumo de açúcar e adoçantes dietéticos, prevaleceu no $2^{\circ}$ semestre o consumo do primeiro e no $8^{\circ}$, o segundo. Observou-se que os alunos do $8^{\circ}$ semestre apresentaram hábitos alimentares mais adequados de acordo com os guias alimentares, talvez uma conseqüencia dos conhecimentos obtidos durante a graduação.

BENEVENUTO e col. (2001) realizaram uma pesquisa com 40 alunas do Curso de Nutrição com idade entre 18 e 41 anos, em uma universidade particular, em Uberaba, com o objetivo de analisar a ingestão alimentar dessas estudantes e verificar a adequação de sua dieta. Verificaram que 7,5\% encontravam-se com IMC (Índice de Massa Corporal) abaixo de 18,5 e $15 \%$ com IMC acima de 25 . Quanto ao valor calórico, apenas $17,5 \%$ consumiram o recomendado. Em relação à ingestão das vitaminas A e C, 35\% e 55\% dos alunos respectivamente atingiram as recomendações, enquanto que somente $7,5 \%$ alcançaram as recomendações de cálcio e $15 \%$, de ferro.

Com o objetivo de descrever o perfil lipídico e verificar sua relação com fatores de risco para doenças cardiovasculares em estudantes de uma universidade pública de São Paulo, foi realizado um estudo transversal nos anos de 1997 e 1998, com estudantes do curso de nutrição, com idades entre 17 e 25 anos. As dietas dos estudantes apresentaram-se inadequadas em relação à proteína, gordura total, gordura saturada, sódio e fibras (FISBERG e col. 2001). 


\subsection{O nutricionista como educador/orientador em saúde}

A educação pode ser definida como o processo de ensino, treinamento e facilitação. É a troca de informações entre o educador e o educando, utilizando uma linguagem de fácil entendimento, dentro de um ambiente que conduz ao aprendizado (ZIWIAN 1999).

A Educação em Saúde pode ser entendida como uma estratégia de promoção de saúde, a qual foi definida na Primeira Conferência Internacional de Promoção da Saúde realizada em Ottawa, Canadá, 1986 , como sendo o processo que capacita a comunidade à atuar na melhoria de sua qualidade de vida e saúde, com uma participação maior no controle desse processo (MINSTÉRIO DA SAÚDE 2000).

O objetivo da Educação em Saúde, visando à Promoção da Saúde, é capacitar os educandos para atuarem como agentes transformadores e participantes de movimentos que defendam a preservação e a sustentabilidade do meio-ambiente, que lutem por melhores condições de vida e saúde para ter maior acesso às informações em saúde, à cultura e ao lazer e pela garantia de que o Estado cumpra seus deveres para com os cidadãos, baseados na Constituição Federal (IERVOLINO 2000).

A educação nutricional está inserida na educação em saúde, e tem como finalidade a formação de atitudes e práticas ligadas à saúde. A educação nutricional incentiva o consumo de alimentos saudáveis, tais como frutas, hortaliças e recomenda evitar 
guloseimas, gorduras saturadas, e de uma maneira geral, alimentos com baixo valor nutritivo. $O$ objetivo principal da educação nutricional é a melhoria da saúde por meio da promoção de hábitos alimentares adequados, eliminação de práticas dietéticas insatisfatórias, introdução de melhores práticas de higiene e uso mais eficiente dos recursos alimentares (MOTTA e BOOG 1988). Tem como objetivo final a promoção da saúde do indivíduo e da comunidade (BARTRINA 1995).

O nutricionista é o profissional que, ao exercer o papel de educador em nutrição, em todas as suas áreas de atuação, pode contribuir para a modificação das práticas alimentares e, consequentemente, para a melhoria da qualidade de vida do individuo (MOTTA e BOOG 1988). Para facilitar esse processo, o educador nutricional deve fornecer apoio emocional, assim como dados de conhecimento para a mudança, bem como utilizar técnicas motivacionais criativas. A educação nutricional deve resultar em mudanças comportamentais específicas às necessidades e à situação de cada indivíduo. (ZIWIAN 1999).

Segundo FREIRE (1998), "ensinar exige a corporeificação das palavras pelo exemplo", ou seja, "pensar certo é fazer certo". A autenticidade da fala do educador deve se traduzir em práticas com a fala consistentes. Logo, do educador, em nutrição espera-se comportamento alimentar compativel com a saúde, também respeitadas as suas necessidades e situação específicas.

Por tudo o que foi explanado anteriormente, acredita-se que alunos ingressantes em cursos de Nutrição apresentem consumo alimentar e estado nutricional semelhantes aos alunos de outros cursos .Porém com o decorrer do curso, em função dos conhecimentos adquiridos, espera-se que seu o estado nutricional e o 
consumo alimentar dos alunos do curso de nutrição venham a sofrer mudanças positivas, quando comparados com os alunos de outros cursos de graduação.

Devido à escassez de literatura em nível nacional e internacional sobre o estado nutricional e consumo alimentar de estudantes universitários, evidencia-se a importância do presente estudo, em especial entre alunos do curso de Nutrição, visto que compete a estes profissionais orientar $\mathrm{e} / \mathrm{ou}$ educar $\mathrm{o}$ indivíduo e a população quanto à manutenção ou obtenção de um estado nutricional adequado. 


\section{OBJETIVOS}




\subsection{Geral}

- Verificar o estado nutricional e o consumo alimentar de estudantes de dois cursos de áreas distintas em uma instituição particular de ensino superior.

\subsection{Especificos}

- Avaliar e comparar o estado nutricional dos estudantes dos cursos de Nutrição e Letras;

- Avaliar e comparar o consumo alimentar com relação a energia, proteina, cálcio e ferro de todos os estudantes;

- Descrever os principais grupos de alimentos consumidos por todos os estudantes;

- Verificar e comparar as mudanças ao longo do tempo no estado nutricional, consumo alimentar e nas caracteristicas gerais entre os estudantes dos cursos de nutrição e letras. 


\subsection{Tipo de Estudo}

Este estudo é do tipo longitudinal, ou seja, de seguimento. Os periodos de coleta dos dados foram os meses de março e abril de 2003 e março e abril de 2004.

\subsection{Local de Estudo}

A pesquisa foi realizada em uma Instituição Particular de Ensino Superior (IPES) localizada no Municipio de Santos, no litoral do Estado de São Paulo. Esta cidade localiza-se na Ilha de São Vicente, junto ao municipio de mesmo nome. Possui $271 \mathrm{~km}^{2}$ de área total, com 39,4 $\mathrm{km}^{2}$ de zona insular, com 417.983 habitantes. Além disso, é neste municipio onde se localiza o maior porto da América Latina, com $154 \mathrm{~km}$ de extensão (PREFEITURA MUNICIPAL DE SANTOS 2004).

Santos apresenta como atividades econômicas o porto, comércio, pesca e turismo. Com relação à área turistica, possui 18 hotéis e flats, 87 bares e restaurantes, 109 agèncias bancárias, 7 shoppings e centros comerciais, 1 centro de convenções. Há ainda 7 universidades, supermercados, museus, centros culturais, bibliotecas, teatros, cinemas (PREFEITURA MUNICIPAL DE SANTOS 2004).

\subsection{População de estudo}

A pesquisa foi realizada com os alunos matriculados no periodo matutino, dos $3^{\circ}$ e $5^{\circ}$ semestres em 2003 e 2004 respectivamente, dos cursos de Nutrição e Letras (Inglês). 


\section{Curso de Nutrição}

O curso de Nutrição dessa IPES é relativamente novo tendo sido reconhecido em 2002. É oferecido no periodo matutino, com duração de 8 semestres, disponibilizando 80 vagas anualmente. Apresenta como objetivo: "proporcionar a formação de um profissional imbuido no cultivo de valores humanos e da ética cristã, bem como tecnicamente competente, reflexivo, critico, comprometido com a sociedade em que está inserido política e socialmente, atuando para a promoção, manutenção da saúde e qualificado para as diversas áreas da alimentação e da nutrição voltado à problemática regional, nacional, e internacional ${ }^{1}$

\section{Curso de Letras}

Ao contrário do curso de Nutrição, o curso de Letras foi reconhecido em 1997. É oferecido nos períodos matutino e noturno, com duração de 8 semestres e oferece 60 vagas por período. Tem como objetivos "formar o professor crítico consciente de seu papel de mediador de transformação na sociedade, envolvido, portanto, com a situação; possibilitar o exercício docente fundamentado através de um conjunto de competências lingüisticas, comunicativas e literárias; criar a atitude dialógica entre as diferentes linguagens e formas de conhecimento, dando ênfase à linguagem verbal; aprofundar, num processo interativo, a reflexão sobre o conhecimento já acumulado, a realidade social e a própria atuação profissional, continuadamente passivel de aperfeiçoamento mediante a investigação científica, que proporciona ao professor e ao aluno a oportunidade de aperfeiçoarem-se em busca de novos conhecimentos”. 
Foi selecionado o curso de Letras - Inglès por não ser da área da saúde e por apresentar corpo discente semelhante ao de Nutrição no que se refere à faixa etária, predominância de alunos do sexo feminino, número de alunos por série, periodo em que o curso é ministrado, duração do curso.

\subsection{Coleta de dados}

A coleta de dados foi precedida de procedimentos considerados fundamentais referentes às questões técnicas e éticas. Foi solicitada permissão aos diretores de cada curso da IPES e, aos coordenadores dos cursos de Nutrição e Letras, antes do contato com os alunos. Em seguida contatou-se um professor de cada curso para autorizar a coleta dos dados no horário de suas respectivas aulas.

\subsection{Variáveis de estudo}

3.5.1 Caracteristicas gerais da populacão: para caracterizar a população de estudo foram coletadas as seguintes informações:

- Idade: considerando a data de nascimento e data da entrevista

- $\operatorname{sexo}$

- Renda familiar: em faixas de salário minimo.

- Número de pessoas residentes no domicilio

- Motivos da escolha pelo curso em questão

3.5.2 Hábitos Alimentares e Estilo de Vida: foi verificado o hábito de realizar dietas modificadas nos últimos 6 meses, bem como quem indicou; utilização de suplemento alimentar (tipo e a freqüência), refeiçōes realizadas diariamente (tipo e local), prática de atividade física (tipo e freqüência), ingestão diária de água. 
Todas as questões anteriormente descritas foram anotadas em formulário próprio (Anexo 1). Os alunos preencheram o formulário em 2003 e 2004, com exceção da questão "motivos que o levaram a escolher o curso", que não foi colhida em 2004. Participaram da pesquisa somente os alunos que estiverem presentes em 2003 e 2004.

\subsubsection{Estado Nutricional}

Para a determinação do estado nutricional, foi utilizado o indice de massa corporal (IMC) [peso $(\mathrm{kg}) /$ altura $^{2}(\mathrm{~m})$ ], sendo realizadas medições de peso e altura, utilizando-se os procedimentos recomendados pela World Health Organization (WHO 1995):

peso: todos os estudantes vestiam roupas leves e estavam descalços. A medida do peso foi realizada com balança eletrônica Plenna ${ }^{\circledR}$, portátil, com capacidade de $150 \mathrm{~kg}$ e precisão de $100 \mathrm{~g}$.

estatura: foi medida com o auxilio de estadiômetro portátil Seca $\circledast$ graduado em décimos de centímetros, fixado em plataforma vertical.

As medidas acima descritas foram realizadas pela pesquisadora com o auxilio de duas alunas do último ano $\left(7^{\circ}\right.$ semestre) do curso de Nutrição (uma em 2003 e a outra em 2004) previamente treinadas.

Para a classificação do estado nutricional segundo o IMC foram adotados como referência os valores recomendados pela World Health Organization (2000) apresentados no Quadro 1: 
Quadro 1 - Classificação do estado nutricional em adultos de acordo com o IMC, WHO (2000)

\begin{tabular}{|c|c|}
\hline $\begin{array}{l}\text { CLASSIFICAÇÃO DO ESTADO } \\
\text { NUTRICIONAL }\end{array}$ & $\operatorname{IMC}\left(\mathrm{kg} / \mathrm{m}^{2}\right)$ \\
\hline Baixo Peso 3 (grave) $^{*}$ & $\mathrm{IMC}<16$ \\
\hline Baixo Peso 2 (moderado)* & IMC $\geq 16$ e $<17$ \\
\hline Baixo peso 1 (leve) ${ }^{\star}$ & $\mathrm{IMC} \geq 17 \mathrm{e}<18,5$ \\
\hline Normalidade & 18,5 a 24,9 \\
\hline Sobrepeso & $\geq 25$ \\
\hline Pré Obeso & 25,0 a 29,9 (aumentado $\left.\mathrm{RM}^{* *}\right)$ \\
\hline Obeso Classe I & 30,0 a 34,9 (moderado RM) \\
\hline Obeso Classe II & 35,0 a 39,9 (grave $R M$ ) \\
\hline Obeso Classe III & $\geq 40 \quad$ (muito grave $R M$ ) \\
\hline
\end{tabular}

Obs: esta classificaçāo é baseada na associaçāo existente entre IMC e morbidade: quanto maior o IMC, maior o risco de morbidade (doenças como diabetes, hipertensão, doenças cardiovasculares)

*: Classificaçāo de acordo com WHO (1995)

**: RM= risco de morbidade

Porém em função do pequeno tamanho da amostra para ambos os cursos e para tornar possivel a análise estatistica, a classificação do estado nutricional foi renomeada da seguinte forma:

Quadro 2: Classificação do estado nutricional de acordo com o IMC

\begin{tabular}{|l|l|}
\hline \multicolumn{1}{|c|}{$\begin{array}{c}\text { CLASSIFICAÇÃO DO ESTADO } \\
\text { NUTRICIONAL }\end{array}$} & \multicolumn{1}{c|}{ IMC $\left(\mathbf{k g} / \mathbf{m}^{\mathbf{2}}\right)$} \\
\hline Baixo Peso & $<18,5$ \\
\hline Normalidade & 18,5 a 24,9 \\
\hline Excesso de Peso & $\geq 25$ \\
\hline
\end{tabular}


Apesar de em 2003 alguns individuos apresentarem idade $\leq 19$ anos e, portanto, serem considerados adolescentes de acordo com a definição da Organização Mundial da Saúde (WHO 1995), foi utilizada a classificação citada acima, para individuos adultos, com o objetivo de tornar possivel a análise dos dados, pois tratava-se de uma amostra pequena, tanto a de adolescentes como o total da população estudada.

O peso corporal foi aferido em 2003 e 2004. Porém por tratar-se de uma população de estudantes com idade $\geq 18$ anos, não estão mais em fase de crescimento longitudinal (WHO 1995) e desta forma, a estatura foi mensurada somente em 2003, sendo considerada a mesma medida em 2004 para o cálculo do IMC. Os dados de peso e estatura foram anotados em formulário próprio (Anexo 2).

\subsubsection{Consumo alimentar}

Para verificar o consumo alimentar dos estudantes foi adotado - Registro Alimentar. Os estudantes foram orientados (Anexo 3) a anotar em formulário próprio (Anexo 4) todos os alimentos/bebidas consumidos em um periodo de 3 dias não consecutivos, sendo um deles Sábado ou Domingo, para melhor avaliar o consumo médio habitual desses estudantes.

A pesquisadora agendou um dia para que os alunos entregassem os registros alimentares preenchidos. Com o auxílio de duas alunas do último ano ( $7^{\circ}$ semestre) do curso de Nutrição (uma em 2003 e outra em 2004) os registros eram conferidos um a um, juntamente com o entrevistado para que houvesse maior exatidão das informações fornecidas e se fizessem as correções necessárias. Houve a necessidade de 7 ou 8 retornos, em ambos os periodos de avaliação, aos locais do estudo (os cursos são ministrados em locais/endereços 
diferentes) para o recebimento de todos os registros alimentares preenchidos.

Os alimentos e/ou preparações relatados pelos alunos foram posteriormente convertidos, de medidas caseiras para peso (gramas) e os dados desses alimentos foram transformados em nutrientes utilizando-se o "software" Virtual Nutri versão 1.0 (PHILIPPI e col. 1996). Quando os alimentos e/ou preparações apresentavam diferentes tamanhos de porções (por ex: fatia pequena, média, grande), adotaram-se valores médios.

Os alimentos e/ou preparações que não constavam do software, foram retirados da Tabela de Medidas Caseiras de PINHEIRO e col. (1994) e (2004) e de rótulos dos produtos, sendo os dados acrescentados ao banco do programa.

Os alimentos e/ou preparações que possuissem mais de uma marca comercial disponivel no software, optou-se por aqueles com maior número de informações quanto aos aspectos nutricionais.

$\mathrm{Na}$ análise da dieta consumida pelos estudantes verificou-se a média da distribuição relativa dos macronutrientes (proteinas, hidratos de carbono e lipídios) ao valor calórico total (VCT), bem como os valores médios de energia e dos micronutrientes - cálcio e ferro.

Além da análise quantitativa da dieta, foi verificada também os principais grupos de alimentos consumidos pelos alunos de ambos os cursos, utilizando-se como padrão de referência a Pirâmide Alimentar adaptada à população brasileira, conforme se observa no quadro 3 . 
Quadro 3: Grupos de alimentos e respectivas porções segundo a Pirâmide Alimentar adaptada à população Brasileira.

\begin{tabular}{|l|c|}
\hline \multicolumn{1}{|c|}{ GRUPO DE ALIMENTOS } & $\begin{array}{c}\text { NÚMERO DE PORÇÕES } \\
\text { DIÁRIA } \\
\text { RECOMENDADA }\end{array}$ \\
\hline Grupo 1: pães cereais, raizes e tubérculos & 5 a 9 \\
\hline Grupo 2: Hortaliças (verduras e legumes) & 4 a 5 \\
\hline Grupo 3: Frutas & 3 a 5 \\
\hline Grupo 4: Carnes e ovos & 1 a 2 \\
\hline Grupo 5: Leite e derivados & 3 \\
\hline Grupo 6: Leguminosas & 1 \\
\hline Grupo 7: Òleos e gorduras & 1 a 2 \\
\hline Grupo 8: Açúcares e doces & 1 a 2 \\
\hline
\end{tabular}

Fonte: PHILIPPI e col. 1999.

Além desses grupos presentes na pirâmide, foi considerado também um outro grupo, o qual não faz parte desse guia alimentar: Grupo 9: bebida alcoólica

Para avaliar a qualidade da dieta considerou-se "porções" o número de "citações" de cada alimento consumido, método utilizado por GAMBARDELLA (1995), para descrever as porções dos alimentos apresentados no Registro Alimentar de Três dias.

Consideraram-se os valores médios diários, calculados sobre o número total de citações de cada grupo alimentar, relatado nos três registros alimentares.

\subsection{Análise Estatistica}

Para a análise estatística foi utilizado o software SPSS (Statistical Package for the Social Sciences) for Windows, versão 11.0, com exceção da Análise de Variância (ANOVA) de Medidas Repetidas, para a qual foi utilizado o software Statistica, versão 5.5 . 
Foram realizados os seguintes testes para a comparação entre os estudantes dos cursos de Nutrição e Letras em 2003:

- Teste U de Mann Whitney (DORIA FILHO 2003): foi calculado para a comparação das distribuições entre os alunos dos cursos para as seguintes variáveis quantitativas: número de pessoas do domicilio, prática de atividade física (número de vezes na semana), consumo de água (número de copos diariamente), IMC, idade, valor calórico total da dieta (VCT), bem como dos nutrientes carboidratos $(\%)$, proteínas $(\%)$, lipidios (\%) (todos como porcentagem em relação ao VCT) cálcio (mg) e ferro (mg).

- Teste Exato de Fisher (DORIA FILHO 2003): foi utilizado para a comparação entre os alunos dos cursos nas seguintes variáveis qualitativas: sexo, hábito de fazer dieta, utilização de suplemento alimentar, hábito de realizar as refeições (desjejum, lanche da manhã, almoço, lanche da tarde, jantar e ceia).

- Teste do Qui Quadrado (DORIA FILHO 2003): foi usado para a comparação entre os alunos dos cursos nas variáveis qualitativas descritas em categorias: renda e IMC.

- Teste de McNemar (DORIA FILHO, 2003): neste caso, foi utilizado para verificar as mudanças ocorridas para as variáveis qualitativas dos estudantes dos cursos, entre os anos de 2003 e 2004.

- Análise de Variância (ANOVA) de Medidas Repetidas (DORIA FILHO 2003): neste estudo, o teste ANOVA com repetição foi 
aplicado para se verificarem as mudanças, entre os anos de 2003 e 2004, ocorridas no consumo alimentar (calorias, proteínas, lipídios, água) dentro do mesmo curso (Nutrição 2003 X Nutrição 2004, Letras $2003 X$ Letras 2004) e comparando-se os diferentes cursos (Nutrição $X$ Letras) nos periodos de avaliação (2003 e 2004).

- Teste de Friedmam (DORIA FILHO 2003): neste caso específico, para analisar as mudanças nas variáveis de consumo de carboidratos, cálcio e ferro, e para o Índice de Massa Corporal foi aplicado o Teste de Friedman, pois elas não apresentavam homogeneidade nas variâncias, e por este motivo não foi possivel aplicar o Teste ANOVA com repetição. Para se verificar a homogeneidade destas variáveis quantitativas, foi aplicado o Teste de Levene.

Para todos os testes estatisticos realizados foi adotado nivel de significância de $5 \%(a=0,05)$.

\subsection{Questões Éticas}

Foram considerados os procedimentos éticos da Resolução 196/96 do Conselho Nacional da Saúde/Ministério da Saúde (BRASIL 1997). O projeto foi aprovado pelo Comitê de Ética em Pesquisa (COEP) da Faculdade de Saúde Pública/USP, em 19/09/2002 (Anexo 5). Os estudantes firmaram o Termo de Consentimento Livre e Esclarecido (Anexo 6). 


\subsection{Colheita do $1^{\circ}$ periodo -2003}

\subsubsection{Caracteristicas Gerais}

O curso de Letras da Instituição de Ensino (IE), contava em 2003 com 25 alunos, tendo participado do estudo 84\% (21). Três alunos não estavam presentes em nenhum dos dias da coleta dos dados e um recusou-se a participar da pesquisa, havendo, portanto, uma perda de $16 \%$. Todos os alunos do curso de Nutrição (30 alunos) matriculados participaram da pesquisa.

Os motivos principais relatados pelos alunos para a escolha do curso de Letras foram o fato de gostarem de leitura, escrita e curiosidade de saber como se expressar no dia a dia, ou porque pretendem lecionar. Seis alunos não responderam à questão. Os relatos completos dos alunos encontram-se anexo (Anexo 7).

No caso dos alunos do curso de Nutrição, os principais motivos relatados para a escolha do curso relacionaram-se à preocupação com a alimentação, saúde, bem estar físico; ter conhecimento para poder ajudar as pessoas na melhoria da saúde, utilizando-se dos alimentos para isso, além de alguns possuirem identificação pessoal, associado ao prazer em lidar e conhecer os alimentos, de descobrir os beneficios e os maleficios que certos alimentos podem ocasionar à saúde. Cinco alunos não responderam à questão. Os relatos completos encontram-se anexo (Anexo 8).

Pode ser observado a predominância do sexo feminino em ambos os cursos, não havendo diferença estatisticamente significante entre eles (Tabela 1). 
Tabela 1: Distribuição do número e proporção dos alunos segundo sexo e tipo de Curso, 2003.

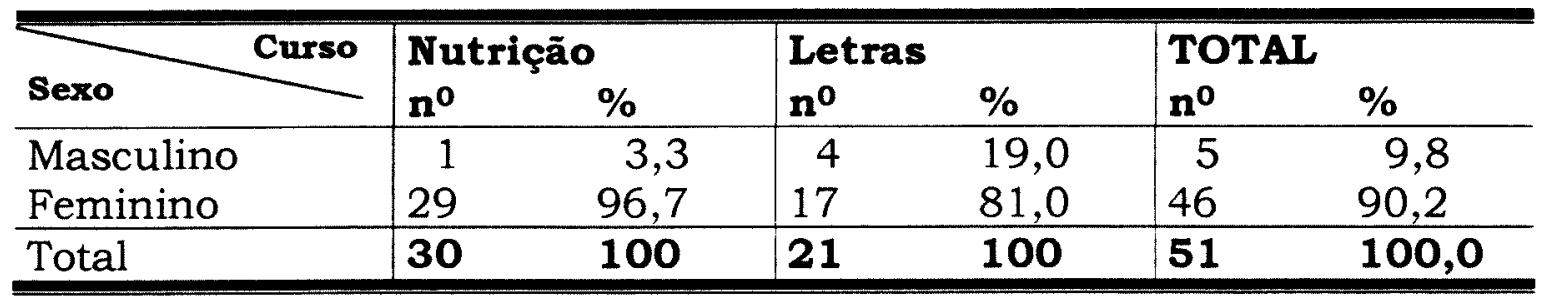

Teste exato de Fisher $(p=0,146)$

Verificou-se que a maior parte dos alunos de ambos os cursos apresentavam renda familiar entre 7 e 11,9 salários minimos (SM Inão havendo diferença estatisticamente significante entre eles (Tabela 2).

Tabela 2: Distribuição do número e proporção dos alunos segundo renda familiar em SM (salários mínimos) e tipo de Curso, 2003.

\begin{tabular}{|c|c|c|c|c|c|c|}
\hline $\begin{array}{lll} & \text { Curso } \\
\text { Renda } & \end{array}$ & $\begin{array}{l}\text { Nut } \\
n^{0}\end{array}$ & $\%$ & $\begin{array}{l}\text { Letras } \\
\text { no }^{\mathbf{2}}\end{array}$ & $\%$ & $\begin{array}{l}\text { TOTAL } \\
n^{0}\end{array}$ & $\%$ \\
\hline Até 6,9 SM & 5 & 17,9 & 5 & 25,0 & 10 & 20,8 \\
\hline 7 a $11 \mathrm{SM}$ & 13 & 46,4 & 11 & 55,0 & 24 & 50,0 \\
\hline$>11 \mathrm{SM}$ & 10 & 35,7 & 4 & 20,0 & 14 & 29,2 \\
\hline Total & $28^{\star}$ & 100,0 & $20 * *$ & 100,0 & 48 & 100,0 \\
\hline
\end{tabular}

Teste do Qui Quadrado $(\mathrm{p}=0,486){ }^{*}$ dois alunos não responderam à questão; ** um alunos não respondeu à questão.

\subsubsection{Hábitos alimentares e estilo de vida}

Verificou-se que a maioria dos alunos de ambos os cursos $(80 \%$ dos de Nutrição e $90,5 \%$ para o curso de Letras) informou não ter realizado dieta modificada nos últimos 6 meses, não havendo diferença estatisticamente significante entre os alunos dos cursos (Teste Exato de Fisher, $p=0,445$ ). 
Uma das alunas do curso de Letras que realizou dieta de emagrecimento, informou ter sido orientada por endocrinologista e a outra aluna, realizou-a por conta própria.

A maior proporção de alunos do curso de Nutrição (20\%) informou ter realizado dieta de emagrecimento, sendo que dois deles com endocrinologista, dois com nutricionista e dois por conta própria.

A grande maioria dos alunos de ambos os cursos não utilizavam suplemento alimentar, (96,7\% para o curso de Nutrição e $90,5 \%$ para o curso de Letras), não havendo diferença estatisticamente significante entre os alunos dos cursos (Teste exato de Fisher, $\mathrm{p}=0,561$ ).

Para o curso de Letras, somente três alunos relataram utilizar suplemento sendo citados os seguintes suplementos: creatina com albumina, aminoácidos com malto dextrina e pó de guaraná e um não respondeu. Em relação à freqüência no uso dos suplementos um deles respondeu ser uma vez ao dia, no caso do pó de guaraná, e os outros dois não responderam.

No caso do curso de Nutrição, apenas um aluno do sexo feminino respondeu usar suplemento alimentar diariamente, sendo este um complexo vitamínico - mineral. 
Tabela 3: Distribuição do número e proporção dos alunos, segundo hábito de realizar as refeições principais (café da manhã, almoço, jantar) e as intermediárias (lanche da manhã, lanche da tarde e ceia) e tipo de curso, 2003.

\begin{tabular}{l|l|l|l|l|c}
\hline Refeições & \multicolumn{2}{|c|}{$\begin{array}{c}\text { Nutrição } \\
\text { (n=30) }\end{array}$} & \multicolumn{2}{c|}{$\begin{array}{c}\text { Letras } \\
\text { (n=21) }\end{array}$} & Valor de $\mathbf{p}^{*}$ \\
\hline & $\mathbf{n}^{\mathbf{0}}$ & $\%$ & $\mathbf{n}^{\mathbf{0}}$ & $\%$ & \\
\hline Café da Manhã & 26 & 86,7 & 17 & 81,0 & 0,702 \\
Lanche da Manhã & 15 & 50,0 & 08 & 38,1 & 0,568 \\
Almoço & 29 & 96,7 & 20 & 95,2 & 1,000 \\
Lanche da Tarde & 23 & 76,7 & 11 & 52,4 & 0,066 \\
Jantar & 25 & 83,3 & 12 & 57,1 & 0,057 \\
Ceia & 09 & 30,0 & 03 & 14,3 & 0,315 \\
\hline
\end{tabular}

*Teste exato de Fisher

A maior proporção dos alunos de ambos os cursos relatou realizar o desjejum $(86,7 \%$ para o curso de Nutrição e 81,0 para o curso de Letras), não havendo diferença estatisticamente significativa entre os alunos dos cursos $(p>0,05)$.

Em relação ao lanche da manhã, metade dos alunos do curso de Nutrição e $38,1 \%$ dos alunos do curso de Letras também possuem o mesmo hábito. Não houve diferença estatisticamente significativa entre os alunos dos cursos.

Para o hábito de realizar o almoço, constatou-se que a maioria dos alunos de ambos os cursos $196,7 \%$ para o curso de Nutrição e $95,2 \%$ para o curso de Letras) possui este hábito, não havendo diferença estatisticamente significante entre os alunos dos cursos. 
Em relação ao hábito de realizar o lanche da tarde, 23,3\% dos alunos do curso de Nutrição e $47,6 \%$ do curso de Letras não possuem este hábito, porém não houve diferença estatisticamente significativa entre os alunos dos cursos. O valor de $\mathrm{p}$ aproximou-se de 0,05 , o que indicaria diferença entre os cursos para esta variável; porém isso não aconteceu provavelmente em função do pequeno tamanho da amostra de ambos os cursos.

No que se refere ao hábito de realizar o jantar, $83,3 \%$ dos alunos do curso de Nutrição relataram ter este hábito, enquanto que para o curso de Letras apenas $57,1 \%$ o referiram, não havendo diferença estatisticamente significativa entre os alunos de cada curso. $O$ valor de $\mathrm{p}$ também aproximou-se de 0,05, o que indicaria diferença entre os alunos dos cursos para esta variável; porém isso não aconteceu provavelmente em função do pequeno tamanho da amostra de ambos os cursos.

A maior porcentagem dos estudantes tanto do curso de Nutrição quanto do curso de Letras relatou não realizar a ceia $(70 \%$ para o curso de Nutrição e $85,7 \%$ para o curso de Letras) não havendo diferença estatisticamente significante entre os alunos de cada curso. 
Tabela 4 : Distribuição do número e proporção dos alunos do curso de Nutrição e Letras segundo o tipo de refeição realizada fora de casa e o local, 2003

\begin{tabular}{l|l|c|c|c|c}
\hline \multicolumn{1}{c|}{$\begin{array}{c}\text { Tipo de } \\
\text { refeição }\end{array}$} & \multicolumn{1}{|c|}{$\begin{array}{c}\text { Local } \\
\text { (n=17) } \\
\mathbf{( 5 6 , 6 7 \% )}\end{array}$} & \multicolumn{2}{c|}{$\begin{array}{c}\text { Letras } \\
\text { (n=13) } \\
(\mathbf{6 1 , 9 \% )}\end{array}$} \\
\hline $\begin{array}{l}\text { Lanches } \\
\text { (manhã e/ou } \\
\text { tarde) }\end{array}$ & $\begin{array}{l}\text { Faculdade/local de } \\
\text { trabalho }\end{array}$ & 13 & 76,47 & 9 & 69,20 \\
\hline Almoço & $\begin{array}{l}\text { Local de } \\
\text { trabalho/restaurante }\end{array}$ & 1 & 5,88 & 1 & 7,7 \\
\hline $\begin{array}{l}\text { Almoço e } \\
\text { lanches }\end{array}$ & $\begin{array}{l}\text { Local de } \\
\text { trabalho/faculdade } \\
\text { restaurante }\end{array}$ & 1 & 5,88 & 1 & 7,7 \\
\hline Jantar & Local de trabalho & - & - & 1 & 7,7 \\
\hline $\begin{array}{l}\text { Jantar e } \\
\text { Lanches }\end{array}$ & Faculdade/pizzaria & 2 & 11,77 & - & - \\
\hline $\begin{array}{l}\text { Almoço, jantar } \\
\text { e lanches }\end{array}$ & Faculdade & - & - & 1 & 7,7 \\
\hline \hline
\end{tabular}

Pode ser observado pela tabela 4 que $61,9 \%$ dos alunos do curso de Letras realizam uma das refeições fora de casa, sendo que a maioria dos alunos $(69,2 \%)$ realiza fora de casa os lanches intermediários (manhã e/ou tarde), sendo que os locais de maior freqüência relatados foram a faculdade e/ou o local de trabalho.

Para o curso de Nutrição, $56,67 \%$ dos alunos relataram realizar uma das refeições fora do domicílio. Pode ser observado que a maioria $(76,47 \%)$ dos alunos realiza fora de casa os lanches 
intermediários (manhã e/ou tarde), sendo o local de maior freqüência a faculdade e/ou local de trabalho.

Informaram praticar algum tipo de atividade fisica $53,3 \%$ dos alunos do curso de Nutrição e $42,9 \%$ dos alunos do curso de Letras, não havendo diferença estatisticamente significativa entre os alunos dos cursos (Teste Exato de Fisher, p=0,547).

Os tipos de atividade física praticados pelos alunos do curso de Letras estavam igualmente distribuídos, com $11,1 \%$ para cada tipo de atividade: Hidroginástica, Musculação e Dança, Musculação e Ginástica localizada, Caminhar e bicicleta, Musculação e condicionamento físico, Ballet e Jazz, Ginástica, Musculação, Aeróbica e localizada.

Para os alunos do curso de Nutrição, observou-se que os tipos de exercícios f́sicos (musculação e caminhada e bicicleta, natação, handball e musculação, ginástica e dança, caminhadas e natação, surf e ciclismo e natação e caminhadas, musculação e ginástica localizada, musculação e ginástica, musculação, ginástica localizada e caminhadas) apresentaram distribuição semelhante (6,25\% para cada conjunto de atividades) com exceção de caminhadas e ginástica localizada que apresentaram maior porcentagem $(18,75 \%$ para cada uma).

\subsubsection{Estado Nutricional}

Conforme pode ser observado na tabela 5 foi diagnosticada maior proporção de alunos do curso de Letras com excesso de peso corporal $(42,9 \%)$ contra 6,7\% para o curso de Nutrição. Apresentaram diagnóstico "normal" $80 \%$ dos alunos do curso de Nutrição e 47,6\% dos alunos do curso de Letras. Houve, portanto, diferença 
estatisticamente significante entre os estados nutricionais dos alunos de cada um dos cursos.

Tabela 5: Distribuição do número e proporção dos alunos segundo estado nutricional e tipo de Curso, 2003.

\begin{tabular}{|c|c|c|c|c|c|c|}
\hline $\begin{array}{l}\text { Estado Curso } \\
\text { Nutricional }\end{array}$ & $\begin{array}{l}\mathrm{Nu} \\
\mathrm{n}^{\mathrm{O}}\end{array}$ & \% & $\begin{array}{l}\text { Letras } \\
n^{0}\end{array}$ & $\%$ & $\begin{array}{l}\text { TOTAL } \\
\text { no }^{0}\end{array}$ & $\%$ \\
\hline Baixo peso & 4 & 13,3 & 2 & 9,5 & 6 & 11,8 \\
\hline Normal & 24 & 80,0 & 10 & 47,6 & 34 & 66,7 \\
\hline Excesso de Peso & 2 & 6,7 & 9 & 42,9 & 11 & 21,6 \\
\hline Total & 30 & 100,0 & 21 & 100,0 & 51 & 100,0 \\
\hline
\end{tabular}

Teste do Qui Quadrado $(\mathrm{p}=0,008)$

Para a comparação entre os dois cursos nas variáveis quantitativas dispostas na tabela 6 foram considerados as distribuições de freqüência das mesmas. 
Tabela 6: Distribuição dos alunos dos cursos de Nutrição e Letras segundo as variáveis quantitativas, 2003.

\begin{tabular}{|c|c|c|c|c|c|}
\hline VARIÁVEIS & CURSO & $N^{0}$ & MÉDIA & $D P$ & VALORES DE $p^{\star \star}$ \\
\hline $\begin{array}{l}\mathrm{n}^{0} \text { pessoas no } \\
\text { domicílio }\end{array}$ & $\begin{array}{l}\mathrm{N} \\
\mathrm{L}\end{array}$ & $\begin{array}{l}29^{\star \star \star} \\
21\end{array}$ & $\begin{array}{l}4,14 \\
3,33\end{array}$ & $\begin{array}{l}1,25 \\
0,97\end{array}$ & $0,015^{*}$ \\
\hline $\begin{array}{l}\text { Prática de } \\
\text { atividade fisica } \\
\left(\mathrm{n}^{0}\right. \\
\text { vezes/semana) }\end{array}$ & $\mathrm{L}$ & $29^{* \star \star}$ & 1,79 & $\begin{array}{r}2,52 \\
2,12\end{array}$ & 0,664 \\
\hline $\begin{array}{l}\text { Consumo de } \\
\text { água }\left(\mathrm{n}^{\circ} \mathrm{de}\right. \\
\text { copos de } \\
\text { água/dia) }\end{array}$ & $\begin{array}{l}N \\
L\end{array}$ & $\begin{array}{l}29^{* \star \star} \\
21\end{array}$ & $\begin{array}{l}5,82 \\
5,67\end{array}$ & $\begin{array}{l}2,38 \\
3,83\end{array}$ & 0,729 \\
\hline IMC & $\begin{array}{l}\mathrm{N} \\
\mathrm{L}\end{array}$ & $\begin{array}{l}30 \\
21\end{array}$ & $\begin{array}{l}21,40 \\
24,36\end{array}$ & $\begin{array}{l}2,64 \\
4,00\end{array}$ & $0,005^{*}$ \\
\hline Idade & $\begin{array}{l}\mathrm{N} \\
\mathrm{L}\end{array}$ & $\begin{array}{l}30 \\
21\end{array}$ & $\begin{array}{l}20,42 \\
23,95\end{array}$ & $\begin{array}{l}2,96 \\
6,85\end{array}$ & $0,034^{*}$ \\
\hline Energia & $\begin{array}{l}\mathrm{N} \\
\mathrm{L}\end{array}$ & $\begin{array}{l}30 \\
21\end{array}$ & $\begin{array}{l}1864,77 \\
2038,06\end{array}$ & $\begin{array}{l}798,45 \\
972,96\end{array}$ & 0,619 \\
\hline $\begin{array}{ll}\text { Hidratos } & \text { de } \\
\text { Carbono } & (\%)\end{array}$ & $\begin{array}{l}\mathrm{N} \\
\mathrm{L}\end{array}$ & $\begin{array}{l}30 \\
21\end{array}$ & $\begin{array}{l}51,51 \\
50,65\end{array}$ & $\begin{array}{l}4,40 \\
5,88\end{array}$ & 0,515 \\
\hline Proteinas (\%) & $\begin{array}{l}\mathrm{N} \\
\mathrm{L}\end{array}$ & $\begin{array}{l}30 \\
21\end{array}$ & $\begin{array}{l}16,51 \\
16,05\end{array}$ & $\begin{array}{l}3,72 \\
5,29\end{array}$ & 0,444 \\
\hline Lipidios (\%) & $\begin{array}{l}\mathrm{N} \\
\mathrm{L}\end{array}$ & $\begin{array}{l}30 \\
21\end{array}$ & $\begin{array}{l}32,47 \\
34,22\end{array}$ & $\begin{array}{l}, 93 \\
5,05\end{array}$ & 0,320 \\
\hline Cálcio (mg) & $\begin{array}{l}\mathbf{N} \\
\mathrm{L}\end{array}$ & $\begin{array}{l}30 \\
21\end{array}$ & $\begin{array}{l}699,43 \\
823,75\end{array}$ & $\begin{array}{l}395,25 \\
463,33\end{array}$ & 0,280 \\
\hline Ferro (mg) & $\begin{array}{l}N \\
\mathrm{~L}\end{array}$ & $\begin{array}{l}30 \\
21\end{array}$ & $\begin{array}{l}10,34 \\
10,89\end{array}$ & $\begin{array}{l}5,13 \\
6,02\end{array}$ & 0,909 \\
\hline
\end{tabular}

$\mathrm{N}=$ Nutrição, L=Letras, $\mathrm{DP}=$ desvio padrão, " diferença estatisticamente significativa

** Teste de Mann Whitney, ${ }^{\star \star \star} u m$ dos alunos não respondeu à questão 
Para a prática de atividade física ( $\mathrm{n}^{\circ}$ vezes/semana), um dos alunos do curso de Nutrição e dois alunos do curso de Letras não responderam à questão.

Segundo os dados dispostos na tabela 6 , percebe-se que os alunos dos dois cursos, apresentaram-se de maneira semelhante entre si, com exceção das variáveis "número de pessoas que residem no domicílio" onde o curso de Nutrição apresentou maior número $(\mathrm{p}<0,05)$; IMC e idade, com valores maiores para o Curso de Letras $(\mathrm{p}<0,05)$.

\subsection{Colheita do $2^{\circ}$ periodo -2004}

\subsubsection{Caracteristicas gerais}

Para o curso de Nutrição, dos 30 alunos que participaram da pesquisa em 2003, 27 alunos (90\%) estiveram presentes em 2004, visto que 03 alunos abandonaram o curso. Com relação aos alunos do curso de Letras, dos 21 alunos presentes em 2003, apenas 14 $(66,7 \%)$ participaram em 2004 . Tal abandono foi devido à mudança de período matutino para o noturno, evasão e reprovação.

Tabela 7: Distribuição do numero de proporção dos alunos segundo renda familiar em SM (salários mínimos) e tipo de Curso, 2004.

\begin{tabular}{|c|c|c|c|c|c|c|}
\hline Curso & & & Letras & & TOTAL & \\
\hline $\begin{array}{l}\text { Renda } \\
\text { (SM) }\end{array}$ & $\mathrm{n}^{0}$ & $\%$ & $\mathrm{n}^{0}$ & $\%$ & & $\%$ \\
\hline Até $6,9 \mathrm{SM}$ & 7 & 30,4 & 5 & 45,5 & 12 & 35,2 \\
\hline 7 a $11 \mathrm{SM}$ & 7 & 30,4 & 4 & 36,4 & 11 & 32,3 \\
\hline$>11 \mathrm{SM}$ & 9 & 39,2 & 2 & 18,1 & 11 & 32,5 \\
\hline TOTAL & 23 & 100,0 & 11 & 100,0 & 34 & 100,0 \\
\hline
\end{tabular}

Teste do Qui Quadrado $(\mathrm{p}=0,735)$ 
Conforme se nota na tabela 7 , a maior porcentagem dos alunos do curso de Nutrição $(39,1 \%)$ encontrava-se na faixa de renda familiar superior a $11 \mathrm{SM}$, enquanto que para os alunos do curso de Letras, a maior proporção foi de até $6,9 \mathrm{SM}$. Não foi verificada diferença estatisticamente significativa entre os alunos dos cursos $(p>0,05)$. Deve ser destacado que 4 alunos do curso de Nutrição e 3 alunos do curso de Letras não responderam à questão.

\subsubsection{Hábitos Alimentares e Estilo de Vida}

A maioria dos alunos do curso de Nutrição $(77,8 \%)$ e $100 \%$ dos alunos do curso de Letras relataram não ter realizado dieta de emagrecimento nos últimos 6 meses não havendo diferença estatisticamente significativa entre os alunos dos cursos (Teste exato de Fisher, $p=0,08$ ).

Das seis alunas do curso de Nutrição que realizaram dieta nos últimos 6 meses, duas foram orientadas por nutricionista, três fizeram dieta por conta própria e uma não respondeu à questão. Deve ser destacado que esta nutricionista trabalha no ambulatório de Nutrição da própria Universidade, sendo este serviço oferecido a todos os individuos da comunidade de forma gratuita.

A maioria dos estudantes de ambos os cursos $(96,3 \%$ para Nutrição e $85,7 \%$ para Letras) relatou não utilizar suplemento alimentar. Não houve diferença estatisticamente entre os alunos dos cursos para esta variável (Teste exato de Fisher, $p=0,265$ ).

Para o curso de Nutrição, apenas uma aluna relatou usar complexo mineral-vitamínico em cápsulas diariamente. No caso do curso de Letras, um dos alunos relatou usar diariamente 
polivitamínico e sulfato ferroso, por ser gestante, e um relatou uso de complexo vitamínico-mineral em cápsulas diariamente.

Tabela 8: Distribuição do número e proporção dos alunos, segundo hábito de realizar as refeições principais (café da manhã, almoço, jantar) e as intermediárias (lanche da manhã, lanche da tarde e ceia) e tipo de curso, 2004.

\begin{tabular}{l|l|l|l|l|c}
\hline \hline Refeições & \multicolumn{2}{|c|}{$\begin{array}{c}\text { Nutrição } \\
\text { (n=27) }\end{array}$} & \multicolumn{2}{c|}{$\begin{array}{c}\text { Letras } \\
\text { (n=13*) }\end{array}$} & Valor de $\mathbf{p}^{\text {** }}$ \\
\hline & $\mathbf{n}^{\mathbf{0}}$ & $\%$ & $\mathbf{n}^{\mathbf{0}}$ & $\%$ & \\
\hline Café da Manhã & 24 & 88,9 & 11 & 84,6 & 1,000 \\
Lanche da Manhã & 12 & 44,4 & 04 & 30,8 & 0,503 \\
Almoço & 27 & 100 & 13 & 100 & --- \\
Lanche da Tarde & 21 & 77,8 & 08 & 61,5 & 0,451 \\
Jantar & 23 & 85,2 & 08 & 61,5 & 0,120 \\
Ceia & 06 & 22,2 & 03 & 23,1 & 1,000 \\
\hline \hline
\end{tabular}

*um dos alunos não respondeu à questão **Teste exato de Fisher

Conforme se nota na tabela 8 , maior proporção dos alunos do curso de Nutrição $(88,9 \%)$ e do curso de Letras $(84,6 \%)$ referiram realizar o café da manhã. Ao contrário do lanche da manhã que foi informado em menor proporção, tendo sido referido por $44,4 \%$ e $30,8 \%$ respectivamente dos alunos dos cursos de Nutrição e Letras. Não foram detectados diferenças estatisticamente significativas entre os alunos dos cursos $(p>0,05)$.

Ainda conforme a tabela 8 , nota-se que a totalidade dos estudantes de ambos os cursos informaram consumir o almoço, portanto não foi realizado o teste estatístico. 
Pode ser observado na tabela 8 que a maior porcentagem $(77,8 \%)$ dos alunos do curso de Nutrição e do curso de Letras $(61,5 \%)$ informou realizar o lanche da tarde, não havendo diferença estatisticamente significativa entre os alunos dos cursos.

A maior parte dos alunos de ambos os cursos $(85,2 \%$ para Nutrição e $61,5 \%$ para Letras) relatou ter o hábito de realizar o jantar e, ao contrário não consomem a ceia $77,8 \%$ dos alunos do curso de Nutrição e $76,9 \%$ dos alunos do curso de Letras, não havendo diferença estatisticamente significativa entre os alunos dos cursos. 
Tabela 9: Distribuição do número e proporção dos alunos dos cursos de Nutrição e Letras, segundo o tipo de refeição realizada fora de casa e o local, 2004.

\begin{tabular}{l|l|c|c|c|c}
\hline \multicolumn{1}{c|}{$\begin{array}{c}\text { Tipo de } \\
\text { refeição }\end{array}$} & \multicolumn{1}{c|}{ Local } & \multicolumn{2}{c|}{$\begin{array}{c}\text { Nutrição } \\
\text { (n=16) } \\
(\mathbf{5 9 , 2 6 \% )}\end{array}$} & \multicolumn{2}{c}{$\begin{array}{c}\text { Letras } \\
\text { (n=07) } \\
(\mathbf{5 0 \% )}\end{array}$} \\
\hline Café da manhã & Faculdade & - & - & 2 & 28,5 \\
\hline $\begin{array}{l}\text { Lanches (manhã } \\
\text { e/ou tarde) }\end{array}$ & $\begin{array}{l}\text { Faculdade/local de } \\
\text { trabalho/ }\end{array}$ & 10 & 62,5 & 3 & 42,9 \\
\hline Almoço & Restaurante & 1 & 6,25 & - & - \\
\hline $\begin{array}{l}\text { Almoço e } \\
\text { lanches }\end{array}$ & $\begin{array}{l}\text { Faculdade/restaurantel } \\
\text { ocal de trabalho }\end{array}$ & 2 & 12,5 & 1 & 14,3 \\
\hline $\begin{array}{l}\text { Jantar } \\
\text { Local de trabalho/não } \\
\text { respondeu }\end{array}$ & 2 & 12,5 & - & - \\
\hline $\begin{array}{l}\text { Jantar e } \\
\text { Lanches }\end{array}$ & $\begin{array}{l}\text { Faculdade/local de } \\
\text { trabalho }\end{array}$ & - & - & 1 & 14,3 \\
\hline $\begin{array}{l}\text { Almoço, jantar e } \\
\text { lanches }\end{array}$ & $\begin{array}{l}\text { Lanchonete/ } \\
\text { restaurante }\end{array}$ & 1 & 6,25 & - & - \\
\hline \hline
\end{tabular}

A tabela 9 mostra as refeições que são realizadas fora de casa e o local destas refeições para os alunos de Nutrição e Letras. Percebese que a maior proporção dos alunos de ambos os cursos $162,5 \%$ dos alunos do curso de Nutrição e $42,9 \%$ dos alunos do curso de Letras) realizam fora de casa os lanches intermediários (manhã ou tarde) e os locais de maior freqüência relatados foram a faculdade e/ou local de trabalho. 
Em 2004, verificou-se que 51,9\% dos alunos do curso de Nutrição e somente $30,8 \%$ dos alunos do curso de Letras, relataram praticar exercicios físicos. Porêm, não houve diferença estatisticamente significativa entre os alunos dos cursos (Teste Exato de Fisher, $p=0,333$ ). Os exercícios físicos referidos pelos alunos do curso de Nutrição foram desde as caminhadas (03 alunos), RPM (01 aluno), spinning e musculação (01 aluno), musculação (02 alunos), ginástica (02 alunos), andar de bicicleta (01 aluno), ginástica e dança (1 aluno), surf e ciclismo (1 aluno), atè musculação e ginástica (1 aluno).

Para os alunos do curso de Letras, os tipos de atividades fisicas informadas pelos quatro alunos foram: musculação e condicionamento físico e caminhadas, ballet e jazz, ginástica e musculação.

\subsubsection{Estado Nutricional}

Tabela 10: Distribuição do número e proporção dos alunos segundo estado nutricional e tipo de Curso, 2004.

\begin{tabular}{|c|c|c|c|c|c|c|}
\hline $\begin{array}{l}\text { Estado Curso } \\
\text { Nutricional }\end{array}$ & $\begin{array}{l}\text { Nu } \\
\text { no }^{0}\end{array}$ & $\%$ & $\begin{array}{l}\text { Letr } \\
\text { no }\end{array}$ & $\%$ & $\begin{array}{l}\text { TO } \\
\text { no }^{0}\end{array}$ & $\%$ \\
\hline $\begin{array}{l}\text { Baixo peso } \\
\text { Normal } \\
\text { Excesso de Peso }\end{array}$ & $\begin{array}{r}1 \\
25 \\
1\end{array}$ & $\begin{array}{r}3,7 \\
92,6 \\
3,7\end{array}$ & $\begin{array}{l}8 \\
5\end{array}$ & $\begin{array}{l}61,5 \\
38,5\end{array}$ & $\begin{array}{r}1 \\
33 \\
6\end{array}$ & $\begin{array}{r}2,5 \\
82,5 \\
15,0\end{array}$ \\
\hline Total & 27 & 100,0 & $13^{*}$ & 100,0 & 40 & 100,0 \\
\hline
\end{tabular}

Teste do Qui Quadrado $(\mathrm{p}=0,014)$ *A avaliaçāo de um dos alunos foi excluída, pois era gestante.

De acordo com a tabela 10, a maior proporção dos alunos do curso de Nutrição $(92,6 \%)$ e do curso de Letras $(61,5 \%)$ apresentaram-se na faixa de normalidade. Porém, $15 \%$ dos alunos apresentaram-se com excesso de peso, sendo a maior parte deles pertencente ao curso de Letras $(38,5 \%)$. Apenas um aluno do curso 
de Nutrição, apresentou baixo peso, havendo diferença estatisticamente significativa entre os alunos dos cursos. Houve diferença estatisticamente significativa entre os estados nutricionais dos alunos de cada um dos cursos $(p=0,014)$.

Para a comparação entre os estudantes dos cursos nas variâveis quantitativas dispostas na tabela 11 foram considerados as distribuições de freqüência das mesmas.

Tabela 11: Distribuição dos alunos dos cursos de Nutrição e Letras segundo as variâveis quantitativas, 2004.

\begin{tabular}{|c|c|c|c|c|c|}
\hline VARIÁVEIS & CURSO & $N^{O}$ & MÉDIA & $D P$ & VALORES DE $p^{*}$ \\
\hline $\begin{array}{l}\text { Consumo de } \\
\text { água (nº de } \\
\text { copos de } \\
\text { água/dia) }\end{array}$ & $\begin{array}{l}\mathrm{N} \\
\mathrm{L}\end{array}$ & $\begin{array}{l}26 \\
14\end{array}$ & $\begin{array}{l}6,13 \\
5,39\end{array}$ & $\begin{array}{l}2,72 \\
3,38\end{array}$ & 0,769 \\
\hline IMC & $\begin{array}{l}\mathrm{N} \\
\mathrm{L}\end{array}$ & $\begin{array}{l}27 \\
14\end{array}$ & $\begin{array}{l}21,49 \\
23,94\end{array}$ & $\begin{array}{l}2,20 \\
3,84\end{array}$ & 0,063 \\
\hline Energia & $\begin{array}{l}\mathrm{N} \\
\mathrm{L}\end{array}$ & $\begin{array}{l}27 \\
14\end{array}$ & $\begin{array}{l}1789,74 \\
2053,23\end{array}$ & $\begin{array}{l}538,99 \\
738,85\end{array}$ & 0,269 \\
\hline $\begin{array}{l}\text { Hidratos } \\
\text { Carbono }(\%)\end{array}$ & $\begin{array}{l}\mathrm{N} \\
\mathrm{L}\end{array}$ & $\begin{array}{l}27 \\
14\end{array}$ & $\begin{array}{l}52,44 \\
50,73\end{array}$ & $\begin{array}{l}6,77 \\
8,52\end{array}$ & 0,577 \\
\hline Proteinas (\%) & $\begin{array}{l}\mathrm{N} \\
\mathrm{L}\end{array}$ & $\begin{array}{l}27 \\
14\end{array}$ & $\begin{array}{l}15,07 \\
15,57\end{array}$ & $\begin{array}{l}2,75 \\
3,51\end{array}$ & 0,422 \\
\hline Lipidios (\%) & $\begin{array}{l}\mathrm{N} \\
\mathrm{L}\end{array}$ & $\begin{array}{l}27 \\
14\end{array}$ & $\begin{array}{l}32,59 \\
34,01\end{array}$ & $\begin{array}{l}6,32 \\
6,02\end{array}$ & 0,458 \\
\hline Cálcio (mg) & $\begin{array}{l}N \\
L\end{array}$ & $\begin{array}{l}27 \\
14\end{array}$ & $\begin{array}{l}625,25 \\
787,57\end{array}$ & $\begin{array}{l}258,74 \\
546,69\end{array}$ & 0,615 \\
\hline Ferro (mg) & $\begin{array}{l}\mathrm{N} \\
\mathrm{L}\end{array}$ & $\begin{array}{l}27 \\
14\end{array}$ & $\begin{array}{c}9,59 \\
12,92\end{array}$ & $\begin{array}{l}3,47 \\
6,72\end{array}$ & 0,176 \\
\hline
\end{tabular}


Considerando a análise das variáveis quantitativas dispostas na tabela 11 , percebe-se que não houve diferença estatisticamente significativa entre os alunos dos cursos para nenhuma das variáveis analisadas.

4.3 Mudanças de hábitos alimentares e de estilo de vida dos alunos dos cursos de Nutrição e Letras considerando as avaliações em 2003 e 2004.

De acordo com a tabela 12 , as mudanças ocorridas entre os alunos de ambos os cursos no que se refere ao hábito de fazer dieta nos últimos 6 meses não foram estatisticamente significativas.

Tabela 12: Distribuição do número e proporção dos alunos segundo tipo de curso e mudança no hábito de fazer dieta nos ûltimos 6 meses.

\begin{tabular}{|c|c|c|c|c|c|c|}
\hline Dieta 2004 & \multicolumn{2}{|c|}{ Não } & \multicolumn{2}{|c|}{ Sim } & \multicolumn{2}{|c|}{ Total } \\
\hline & $\mathrm{n}^{0}$ & $\%$ & $n^{0}$ & $\%$ & $\mathrm{n}^{0}$ & $\%$ \\
\hline \multicolumn{7}{|l|}{ Nutrição } \\
\hline Não & 19 & 90,5 & 2 & 9,5 & 21 & 100,0 \\
\hline $\operatorname{Sim}$ & 2 & 33,3 & 4 & 66,7 & 6 & 100,0 \\
\hline Total & 21 & 77,8 & 6 & 22,2 & 27 & 100,0 \\
\hline \multicolumn{7}{|l|}{ Letras } \\
\hline Não & 13 & 100,0 & - & - & 13 & 100,0 \\
\hline Sim & 1 & 100,0 & - & - & 1 & 100,0 \\
\hline Total & 14 & 100,0 & 00 & 0,0 & 14 & 100,0 \\
\hline
\end{tabular}

Teste McNemar: Nutricão $(\mathrm{b}=1.000$ ) 
Entre os estudantes de Nutrição 33,3\% dos que faziam dieta na primeira avaliação relataram não estar em dieta de emagrecimento na segunda avaliação. Dos vinte e um alunos que não faziam dieta em 2003, dois passaram a fazer dieta de emagrecimento em 2004 $(p=1,000)$.

Entre os estudantes de Letras foi observada pequena alteração de comportamento quanto à realização de dieta, isto é, os treze estudantes que relataram não fazer dieta de restrições alimentares na primeira avaliação mantiveram suas respostas na segunda avaliação, portanto não foi realizado o teste de MacNemar.

Tabela 13: Distribuição do número e proporção dos alunos segundo tipo de curso e mudança no hábito de usar suplemento alimentar.

\begin{tabular}{|c|c|c|c|c|c|c|}
\hline \multirow{2}{*}{${ }_{2003}^{2004}$} & \multicolumn{2}{|c|}{ Não } & \multicolumn{2}{|c|}{ Sim } & \multicolumn{2}{|c|}{ Total } \\
\hline & $n^{0}$ & $\%$ & $\mathrm{n}^{0}$ & $\%$ & $n^{0}$ & $\%$ \\
\hline \multicolumn{7}{|l|}{ Nutrição } \\
\hline Não & 25 & 96,2 & 1 & 3,8 & 26 & 100,0 \\
\hline Sim & 1 & 100,0 & - & - & 1 & 100,0 \\
\hline Total & 26 & 96,3 & 1 & 3,7 & 27 & 100,0 \\
\hline \multicolumn{7}{|l|}{ Letras } \\
\hline Não & 10 & 83,3 & 2 & 16,7 & 12 & 100,0 \\
\hline Sim & 2 & 100,0 & - & - & 2 & 100,0 \\
\hline Total & 12 & 85,7 & 2 & 14,3 & 14 & 100,0 \\
\hline
\end{tabular}

Teste McNemar: Nutrição $(p=1,000)$; Letras $(p=1,000)$

Conforme se observa na tabela 13 , as mudanças ocorridas no que se refere ao uso de suplemento alimentar entre os alunos de ambos os cursos não foram estatisticamente significativas. Entre os 
alunos do curso de Nutrição apenas um usava suplemento na primeira avaliação. Esse deixou de usar em 2004. Dos vinte e seis alunos que não usavam suplemento em 2003, apenas um passou a usar em 2004 ( $p=1,00)$.

Dois dos estudantes do curso de Letras que usavam suplemento alimentar na primeira avaliação relataram não usar na segunda avaliação. Dos doze alunos que relataram não usar suplemento alimentar em 2004, dois passaram a usar em 2004 $(p=1,00)$.

Tabela 14: Distribuição do número e proporção dos alunos segundo tipo de curso e mudança no hábito de realizar o desjejum.

\begin{tabular}{|c|c|c|c|c|c|c|}
\hline \multirow{2}{*}{$7_{2003}^{20}$} & \multicolumn{2}{|c|}{ Não } & \multicolumn{2}{|c|}{ Sim } & \multicolumn{2}{|c|}{ Total } \\
\hline & $n^{0}$ & $\%$ & $n^{0}$ & $\%$ & $n^{0}$ & $\%$ \\
\hline \multicolumn{7}{|c|}{ Nutrição } \\
\hline Não & 2 & 66,7 & 1 & 33,3 & 3 & 100,0 \\
\hline Sim & 1 & 4,2 & 23 & 95,8 & 24 & 100,0 \\
\hline Total & 3 & 11,1 & 24 & 88,9 & 27 & 100,0 \\
\hline \multicolumn{7}{|c|}{ Letras } \\
\hline Não & - & - & 1 & 100,0 & 1 & 100,0 \\
\hline Sim & 2 & 16,7 & 10 & 83,3 & 12 & 100,0 \\
\hline Total & 2 & 15,4 & 11 & 84,6 & 13 & 100,0 \\
\hline
\end{tabular}

Teste McNemar: Nutrição $(p=1,000)$; Letras $(p=1,000)$

Conforme tabela $14,4,2 \%$ dos alunos dos alunos do curso de Nutrição que realizavam o desjejum na primeira avaliação, relataram não realizar na segunda avaliação. Dos vinte e quatro alunos que relataram fazer o desjejum em 2003, vinte e três alunos continuaram realizando em $2004(\mathrm{p}=1,000)$. 
Com relação aos alunos do curso de Letras, dois alunos que relataram realizar o desjejum em 2003, deixaram de faze-lo em 2004. Dos doze alunos que relataram fazer essa refeição em 2003, dez continuaram realizando em $2004(p=1,000)$. Não foram detectadas diferenças estatisticamente significativas para as mudanças ocorridas entre os alunos de ambos os cursos.

Tabela 15: Distribuição do número e proporção dos alunos segundo tipo de curso e mudança no hábito de realizar o lanche da manhã.

\begin{tabular}{l|cc|cc|cc}
\hline \multirow{2}{*}{2003} & \multicolumn{2}{|c|}{ Não } & \multicolumn{2}{c|}{ Sim } & \multicolumn{2}{c}{ Total } \\
\hline Nutrição & $\mathbf{n}^{0}$ & $\%$ & $\mathbf{n}^{0}$ & $\%$ & $\mathbf{n}^{0}$ & $\%$ \\
\hline Não & & & & & & \\
Sim & 9 & 75,0 & 3 & 25,0 & 12 & 100,0 \\
\hline Total & 6 & 40,0 & 9 & 60,0 & 15 & 100,0 \\
\hline Letras & 15 & $\mathbf{5 5 , 6}$ & $\mathbf{1 2}$ & $\mathbf{4 4 , 4}$ & $\mathbf{2 7}$ & $\mathbf{1 0 0 , 0}$ \\
\hline Não & & & & & & \\
Sim & 7 & 77,8 & 2 & 50,0 & 9 & 69,2 \\
\hline Total & 2 & 22,2 & 2 & 50,0 & 4 & 30,8 \\
\hline
\end{tabular}

Teste McNemar: Nutrição ( $p=0,508)$; Letras $(p=1,000)$

De acordo com a tabela 15, não houve diferença estatisticamente significativa para as mudanças ocorridas em relação ao hábito de realizar o lanche da manhã, entre os alunos de ambos os cursos $(p>0,05)$ 
Entre os alunos do curso de Nutrição $40 \%$ dos que realizavam o lanche da manhã na primeira avaliação, relataram não realizar na segunda avaliação. Dos doze alunos que não realizavam o lanche da manhã em 2003, três alunos passaram a realizar em 2004(p=0,508). Com relação aos alunos do curso de Letras, verificou-se que dois deles que realizavam em 2003 passaram a não consumir essa refeição em 2004. Dos nove alunos que relataram não fazer o lanche da manhã em 2003, dois alunos passaram essa refeição em 2004 $(p=1,000)$.

Não foi necessário calcular o teste de MacNemar com relação à alteração da primeira para a segunda avaliação sobre a realização do almoço, uma vez que o total de alunos de ambos os cursos informaram continuar consumindo essa refeição.

Tabela 16: Distribuição do número e proporção dos alunos segundo tipo de curso e mudança no hábito de realizar o lanche da tarde.

\begin{tabular}{|c|c|c|c|c|c|c|}
\hline \multirow{2}{*}{2003} & \multicolumn{2}{|c|}{ Năo } & \multicolumn{2}{|c|}{$\operatorname{sim}$} & \multicolumn{2}{|c|}{ Total } \\
\hline & $\mathrm{n}^{0}$ & $\%$ & $n^{0}$ & $\%$ & $n^{0}$ & $\%$ \\
\hline \multicolumn{7}{|c|}{ Nutrição } \\
\hline Não & 3 & 42,8 & 4 & 57,2 & 7 & 100,0 \\
\hline Sim & 3 & 15,0 & 17 & 85,0 & 20 & 100,0 \\
\hline Total & 6 & 22,2 & 21 & 77,8 & 27 & 100,0 \\
\hline \multicolumn{7}{|c|}{ Letras } \\
\hline Não & 4 & 80,0 & 1 & 20,0 & 5 & 100,0 \\
\hline Sim & 1 & 12,5 & 7 & 87,5 & 8 & 100,0 \\
\hline Total & 5 & 38,5 & 8 & 61,5 & 13 & 100,0 \\
\hline
\end{tabular}

Teste McNemar: Nutrição ( $p=1,000)$; Letras $(p=1,000)$ 
Para o hábito de realizar o lanche da tarde, as mudanças que ocorreram entre os anos de 2003 e 2004, entre os alunos de ambos os cursos não foram estatisticamente significativas ( $p>0,05)$.

Conforme tabela 16, entre os alunos do curso de Nutrição, 15\% dos que faziam o lanche da tarde na primeira avaliação, passaram a não realizar na segunda avaliação. Dos vinte alunos que afirmaram realizar o lanche da tarde em 2003, dezessete continuaram a fazê-lo em $2004(p=1,000)$.

Para o curso de Letras, $12,5 \%$ dos alunos que faziam o lanche da tarde na primeira avaliação relataram não fazer na segunda avaliação. Dos oito estudantes que relataram fazer o lanche da tarde na primeira avaliação, sete continuaram a realizar na segunda avaliação $(p=1,000)$.

Tabela 17: Distribuição do número e proporção dos alunos segundo tipo de curso e mudança no hábito de realizar o jantar.

\begin{tabular}{|c|c|c|c|c|c|c|}
\hline \multirow{2}{*}{2003} & \multicolumn{2}{|c|}{ Não } & \multicolumn{2}{|c|}{ Sim } & \multicolumn{2}{|c|}{ Total } \\
\hline & $n^{0}$ & $\%$ & $n^{0}$ & $\%$ & $n^{0}$ & $\%$ \\
\hline \multicolumn{7}{|c|}{ Nutrição } \\
\hline Não & 1 & 25,0 & 3 & 75,0 & 4 & 100,0 \\
\hline Sim & 3 & 13,0 & 20 & 87,0 & 23 & 100,0 \\
\hline Total & 4 & 14,8 & 23 & 85,2 & 27 & 100,0 \\
\hline \multicolumn{7}{|c|}{ Letras } \\
\hline Não & 3 & 75,0 & 1 & 25,0 & 4 & 100,0 \\
\hline Sim & 2 & 22,2 & 7 & 77,8 & 9 & 100,0 \\
\hline Total & & 38,5 & 8 & 61,5 & 13 & 100,0 \\
\hline
\end{tabular}


Conforme pode ser observado na tabela 17 , as mudanças ocorridas em relação ao hábito de realizar o jantar não foram estatisticamente significativas para os alunos de ambos os cursos $(p>0,05)$.

Entre os estudantes do curso de Nutrição, $13 \%$ dos que realizavam o jantar na primeira avaliação relataram não realizar na segunda avaliação. Vinte e três alunos que disseram realizar o jantar na primeira avaliação, vinte alunos continuaram a realizá-la na segunda avaliação $(p=1,000)$.

Para os alunos do curso de Letras, $22,2 \%$ dos que realizavam o jantar na primeira avaliação, passaram a não fazer na segunda avaliação. Nove alunos que disseram realizar o jantar na primeira avaliação, sete continuaram a fazê-la na segunda avaliação $(p=1,000)$. 
Tabela 18: Distribuição do número e proporção dos alunos segundo tipo de curso e mudança no hábito de realizar a ceia.

\begin{tabular}{|c|c|c|c|c|c|c|}
\hline \multirow{2}{*}{2003} & \multicolumn{2}{|c|}{ Não } & \multicolumn{2}{|c|}{ Sim } & \multicolumn{2}{|c|}{ Total } \\
\hline & $\mathrm{n}^{0}$ & $\%$ & $n^{0}$ & $\%$ & $n^{0}$ & $\%$ \\
\hline \multicolumn{7}{|c|}{ Nutrição } \\
\hline Não & 18 & 90,0 & 2 & 10,0 & 20 & 100,0 \\
\hline Sim & 3 & 42,8 & 4 & 57,2 & 7 & 100,0 \\
\hline Total & 21 & 77,8 & 6 & 22,2 & 27 & 100,0 \\
\hline \multicolumn{7}{|c|}{ Letras } \\
\hline Não & 10 & 83,3 & 2 & 16,7 & 12 & 100,0 \\
\hline Sim & - & - & 1 & 100,0 & 1 & 100,0 \\
\hline Total & 10 & 76,9 & 3 & 23,1 & 13 & 100,0 \\
\hline
\end{tabular}

Teste McNemar: Nutrição ( $p=1000)$; Letras $(p=0,500)$

Para o hábito de realizar a ceia, as mudanças ocorridas entre os anos de 2003 e 2004 não foram estatisticamente significativas entre os alunos de ambos os cursos $(p>0,05)$.

Entre os alunos do curso de Nutrição, $42,8 \%$ que relataram realizar a ceia na primeira avaliação, disseram não realizar na segunda avaliação. Dos vinte alunos que relataram não realizar a ceia em 2003, dois passaram a realiza-la em 2004 ( $p=1,000$ ).

Para os alunos do curso de Letras, $83,3 \%$ dos alunos que não realizavam a ceia na primeira avaliação, também não faziam na segunda avaliação. Dos doze alunos que não realizavam a ceia na primeira avaliação, dois afirmaram realizar na segunda avaliação $(p=0,500)$. 
Tabela 19: Distribuição do número e proporção dos alunos segundo tipo de curso e mudança na prática de atividade fisica.

\begin{tabular}{|c|c|c|c|c|c|c|}
\hline \multirow{2}{*}{${ }_{2003}^{20}$} & \multicolumn{2}{|c|}{ Não } & \multicolumn{2}{|c|}{ Sim } & \multicolumn{2}{|c|}{ Total } \\
\hline & $n^{0}$ & $\%$ & $n^{0}$ & $\%$ & $n^{0}$ & $\%$ \\
\hline \multicolumn{7}{|c|}{ Nutrição } \\
\hline Não & 8 & 57,2 & 6 & 42,8 & 14 & 100,0 \\
\hline Sim & 6 & 46,2 & 7 & 53,8 & 13 & 100,0 \\
\hline Total & 14 & 51,9 & 13 & 48,1 & 27 & 100,0 \\
\hline \multicolumn{7}{|c|}{ Letras } \\
\hline Não & 7 & 100,0 & - & - & 7 & 100,0 \\
\hline $\operatorname{Sim}$ & 2 & 33,3 & 4 & 66,7 & 6 & 100,0 \\
\hline Total & 9 & 69,2 & 4 & 30,8 & 13 & 100,0 \\
\hline
\end{tabular}

Teste McNemar: Nutrição $(p=1,000)$; Letras $(p=0,500)$

Conforme pode ser observado na tabela acima, para a prática de atividade fisica as mudanças ocorridas de 2003 para 2004 não foram estatisticamente significativas entre os alunos de ambos os cursos $(p>0,05)$.

Entre os alunos do curso de Nutrição, $46,2 \%$ dos alunos que praticavam atividade fisica na primeira avaliação, relataram não praticar na segunda avaliação. Dos quatorze alunos que não praticavam atividade fisica em 2003, seis alunos passaram a praticar em $2004(p=1,000)$.

No caso dos alunos do Curso de Letras, $33,3 \%$ dos alunos que praticavam atividade física na primeira avaliação, relataram não praticar na segunda avaliação. $(p=0,500)$. Dos sete alunos que 
informaram não praticar atividade física em 2003, nenhum passou a praticar atividade física na segunda avaliação $(p=0,500)$.

\subsection{Mudanças do consumo alimentar e do indice de massa corporal dos alunos dos cursos de Nutrição e Letras considerando as avaliações em 2003 e 2004.}

Para verificar se ocorreram mudanças para as variáveis quantitativas entre os anos de 2003 e 2004, e entre os 2 cursos foi realizada a Análise de Variância de Medidas Repetidas (ANOVA). No sentido de testar a homogeneidade das variáveis, realizou-se o Teste de Levene's. Para as variáveis, indice de massa corporal, consumo de hidratos de carbono, de cálcio e de ferro, que não apresentaram homogeneidade, utilizou-se o Teste de Friedman.

Tabela 20: Distribuição dos alunos segundo tipo de curso e consumo médio e desvio padrão de nutrientes no periodo de avaliação.

\begin{tabular}{|c|c|c|c|c|}
\hline \multirow[b]{2}{*}{$\begin{array}{l}\text { Consumo } \\
\text { (médiatDP) }\end{array}$} & \multicolumn{2}{|c|}{ Nutrição } & \multicolumn{2}{|c|}{ Letras } \\
\hline & 2003 & 2004 & 2003 & 2004 \\
\hline Energia (cal) & $1925,19 \pm 788,74$ & $1789,74 \pm 538,99$ & $2157,52 \pm 1061,97$ & $2053,23 \pm 738,85$ \\
\hline $\begin{array}{l}\text { Hidratos de } \\
\text { Carbono (\%) }\end{array}$ & $51,65 \pm 4,36$ & $52,44 \pm 6,77$ & $51,42 \pm 6,36$ & $50,73 \pm 8,52$ \\
\hline Lipidios (\%) & $32,80 \pm 4,71$ & $32,59 \pm 6,32$ & $33,61 \pm 5,76$ & $34,01 \pm 6,02$ \\
\hline Proteinas (\%) & $16,17 \pm 3,35$ & $15,07 \pm 2,75$ & $14,80 \pm 3,23$ & $15,57 \pm 3,51$ \\
\hline Cálcio (mg) & $718,57 \pm 407,30$ & $625,25 \pm 258,74$ & $875,30 \pm 553,23$ & $787,57 \pm 546,69$ \\
\hline Ferro (mg) & $10,83 \pm 5,17$ & $9,59 \pm 3,47$ & $11,37 \pm 7,04$ & $12,92 \pm 6,72$ \\
\hline
\end{tabular}


Não foram detectadas diferenças estatisticamente significativas entre os alunos dos cursos de Nutrição e Letras, no que diz respeito ao valor calórico total da dieta $(p=0,297)$ e nem entre as avaliações de 2003 para $2004(p=0,192)$. Não houve interação estatisticamente significativa entre as avaliações de 2003 e 2004 e os alunos dos cursos $(\mathrm{p}=0,863)$.

No que se refere consumo de carboidratos em relação ao valor calórico total, não houve mudança estatisticamente significativa inter e intra alunos dos cursos, entre as avaliações de 2003 e 2004 ( $p=0,80$ segundo o Teste de Friedman).

Não houve diferença estatisticamente significativa entre os alunos dos cursos no que se refere ao consumo de proteinas em relação ao valor calórico total $(p=0,618)$ e nem entre as avaliações de 2003 para 2004 ( $p=0,777$ ). Não houve interação estatisticamente significativa entre as avaliações de 2003 e 2004 e os alunos dos cursos $(p=0,118)$.

Para a média no consumo de lipídios em relação ao valor calórico total, não houve diferença estatisticamente significativa entre os alunos dos cursos $(p=0,515)$ e nem entre as avaliações de 2003 para $2004(p=0,914)$. Não houve interação estatisticamente significativa entre as avaliações de 2003 e 2004 e os alunos dos cursos $(p=0,733)$.

Não foram encontradas mudanças estatisticamente significativas intra e inter alunos dos cursos, entre as avaliações de 2003 e 2004 ( $p=0,557$ segundo o Teste de Friedman). 
No que diz respeito ao consumo de ferro, não houve mudança estatisticamente significativa inter e intra alunos cursos, entre as avaliações de 2003 e 2004 ( $p=0,59$ segundo o Teste de Friedman).

Tabela 21: Distribuição dos alunos segundo tipo de curso e consumo médio de água (copos/dia) no periodo de avaliação.

\begin{tabular}{l|l|l}
\hline Curso & $\begin{array}{l}\text { Consumo de Água } \\
\text { (copos/dia) (2003) } \\
\text { (Média } \pm \text { DP) }\end{array}$ & $\begin{array}{l}\text { Consumo de Água } \\
\text { (copos/dia) (2004) } \\
\text { (Média } \pm \text { DP) }\end{array}$ \\
\hline Nutrição & $5,80 \pm 2,50$ & $6,14 \pm 2,77$ \\
\hline Letras & $5,64 \pm 3,39$ & $5,39 \pm 3,38$ \\
\hline
\end{tabular}

Para a média no consumo de água, não houve diferença estatisticamente significativa entre os alunos dos cursos $(p=0,602)$ e nem entre as avaliações de 2003 para 2004 ( $p=0,922)$. Não houve interação estatisticamente significativa entre as avaliações de 2003 e 2004 e os alunos dos cursos ( $p=0,525)$.

Tabela 22: Distribuição dos alunos segundo tipo de curso e Índice de Massa corporal médio (IMC) no periodo de avaliação.

\begin{tabular}{|c|c|c|}
\hline Curso & $\begin{array}{l}\text { IMC (2003) } \\
\text { (Média } \pm \text { DP) }\end{array}$ & $\begin{array}{l}\text { IMC (2004) } \\
\text { (Média } \pm \text { DP) }\end{array}$ \\
\hline Nutrição & 20,95 & 21,49 \\
\hline Letras & 23,86 & 23,94 \\
\hline
\end{tabular}

$p=0,114$, nivel de significância estatística segundo o Teste de Friedman 
Para o valor médio do indice de massa corporal (IMC), não houve mudança estatisticamente significativa inter e intra alunos dos cursos, entre as avaliações de 2003 e 2004.

\subsection{Alimentos/Preparações mais consumidos pelos alunos dos cursos de Nutrição e Letras.}

Os gráficos 1 ao 4 mostram as porções médias diárias dos grupos de alimentos consumidos nos períodos de avaliação pelos alunos de Nutrição e Letras, respectivamente.

\section{Gráfico 1: Distribuição dos alunos de Nutrição} segundo porção média consumida dos grupos de alimentos em 2003.

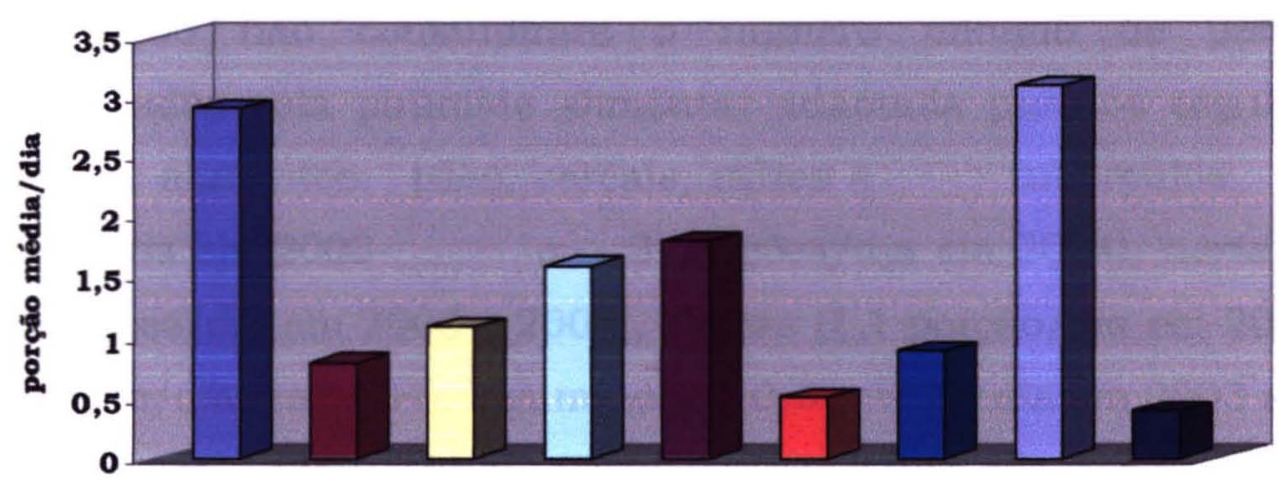

$$
\begin{aligned}
& \square \text { pães, cereais, raizes e tubérculos } \square \text { hortaliças } \\
& \square \text { frutas } \square \text { carnes e ovos } \\
& \text { - leite e derivados } \square \text { leguminosas } \\
& \text { bóleos e gorduras } \square \text { açúcares e doces } \\
& \text { bebida al coólica }
\end{aligned}
$$




\section{Gráfico 2: Distribuição dos alunos do curso de Nutrição segundo porção média consumida dos grupos de alimentos em 2004}

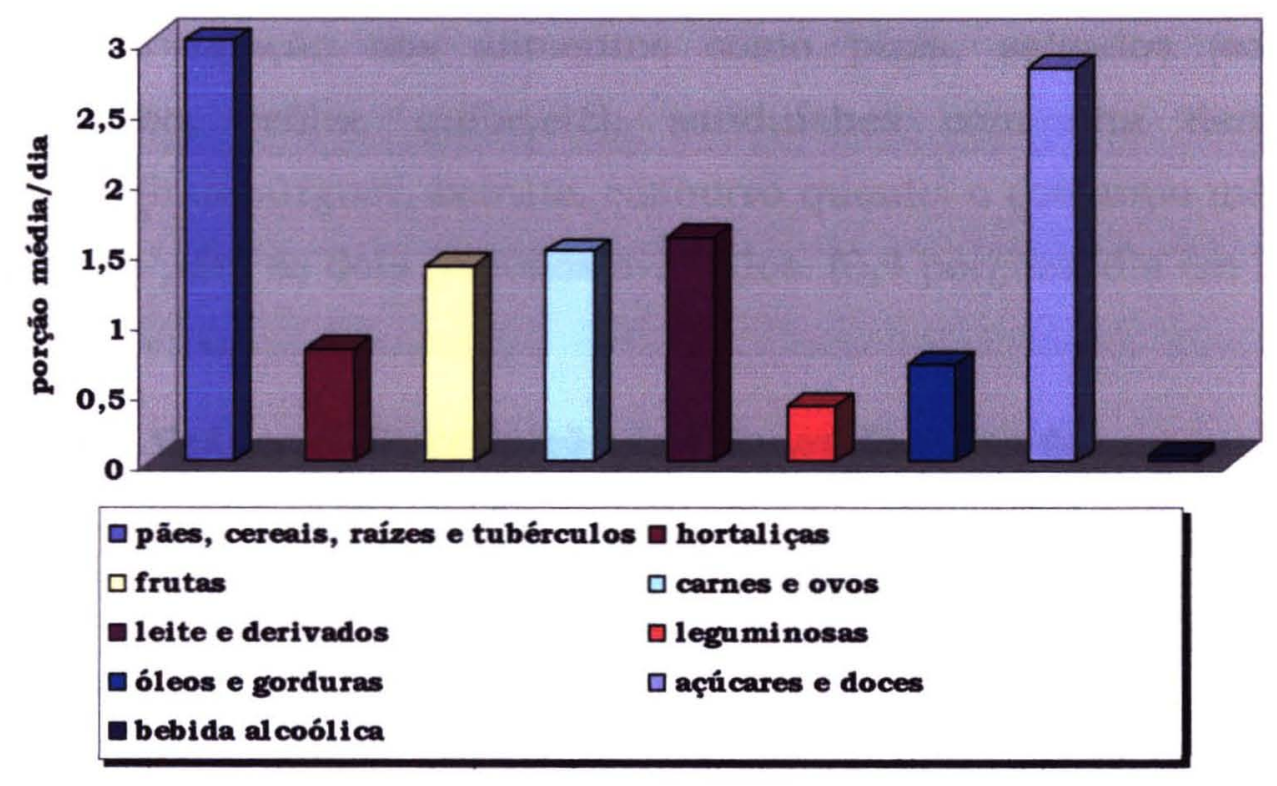

Pode ser observado pelos gráficos 1 e 2 que os alunos do curso de Nutrição não consumiram o número mínimo de porções recomendadas pela pirâmide alimentar adaptada para os seguintes grupos de alimentos: pães, cereais, raízes e tubérculos (2,9 porções/dia em 2003 e 3 porções/dia em 2004), hortaliças (0,8 porções/dia em 2003 e 2004), frutas (1,1 porção/dia em 2003 e 1,4 porção/dia em 2004), leguminosas (0,5 porção/dia em 2003 e 0,4 porção/dia em 2004), leite e derivados (1,8 porção/dia em 2003 e 1,6 porção/dia em 2004), óleos e gorduras (0,9 porção/dia em 2003 e 0,7 porção/dia em 2004). Já para os grupos de alimentos "carnes e ovos" (1,6 porções/dia em 2003 e 1,5 porções/dia em 2004) e "açúcares e doces” (3,1 porção/dia em 2003 e 2,8 porção/dia em 2004), as porções médias consumidas ultrapassaram o valor máximo recomendado pela pirâmide alimentar adaptada à população brasileira.. 
O consumo médio de bebida alcoólica $(0,04$ porções/dia em 2003 e 2004) foi baixo tanto em 2003 quanto em 2004.

Em relação aos alimentos como pizza, salgados (coxinha, salgadinho, esfiha, quibe,etc), sanduíches com alta densidade calórica (hambúrguer, beirute, cachorro quente) o consumo médio foi o mesmo para os dois periodos avaliados. (0,4 porções/dia em 2003 e 2004)

Gráfico 3: Distribuição dos alunos do curso de

Letras segundo porção média consumida dos grupos de alimentos em 2003.

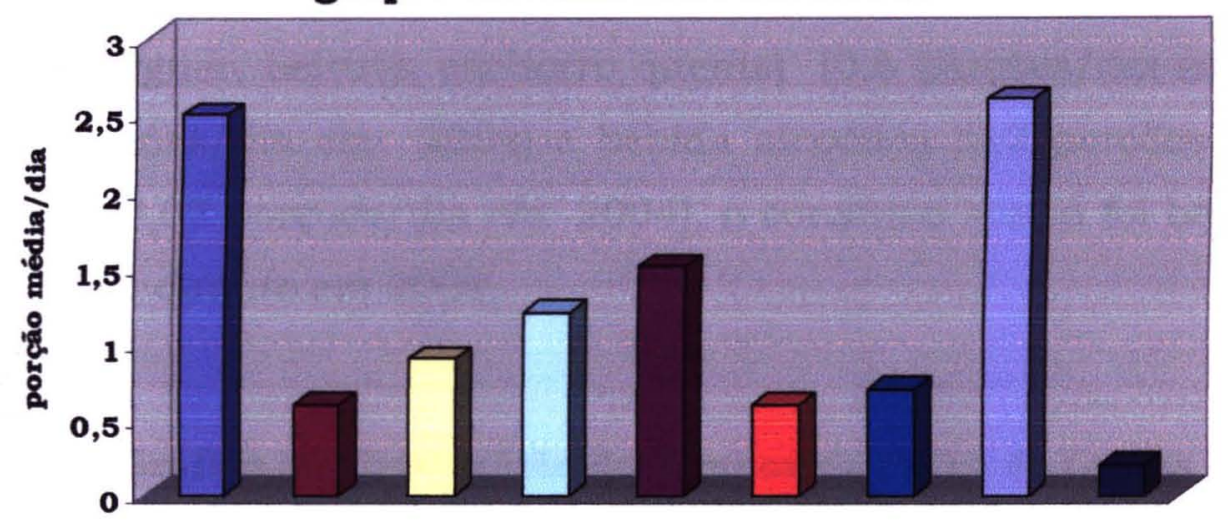

\begin{tabular}{|ll|}
\hline$\square$ pães, cereais, raizes e tubérculos & $\square$ hortal iças \\
$\square$ frutas & $\square$ carnes e ovos \\
$\square$ leite e derivados & $\square$ leguminosas \\
$\square$ óleos e gorduras & $\square$ açúcares e doces \\
$\square$ bebida alcoólica & \\
\hline
\end{tabular}

Pode ser observado pelos gráficos 3 e 4 que os alunos do curso de Letras não consumiram o número mínimo de porções recomendadas pela pirâmide alimentar adaptada para os seguintes grupos de alimentos: pães, cereais, raízes e tubérculos (2,5 porções/dia em 2003 e 2,9 porções/dia em 2004), hortaliças (0,6 porções/dia em 2003 e 0,7 porções/dia em 2004), frutas (0,9 porção/dia em 2003 e 0,5 porção/dia em 2004), leguminosas (0,6 poções/dia em 2003 e 2004), leite e derivados (1,5 
porção/dia em 2003 e 1,9 porção/dia em 2004), óleos e gorduras (0,7 porção/dia em 2003). Em 2004, o consumo médio desse último grupo de alimentos alcançou o valor recomendado (1 porção/dia). Já para os grupos de alimentos "carnes e ovos" (1,2 porções/dia em 2003e 2004) e "açúcares e doces" (2,6 porção/dia em 2003 e 3,0 porção/dia em 2004), as porções médias consumidas ultrapassaram o valor máximo recomendado pela pirâmide alimentar adaptada à população brasileira.

Para os alimentos como pizza, salgados (coxinha, salgadinho, esfiha, quibe,etc), sanduíches com alta densidade calórica (hambúrguer, beirute, cachorro quente) (0,6 porções/dia em $2003 \mathrm{e}$ 0,4 porções/dia em 2004) e bebida alcoólica ( 0,2 porções /dia em 2003 e 0,07 porções/dia em 2004), o consumo médio foi baixo tanto em 2003 quanto em 2004.

\section{Gráfico 4: Distribuição dos alunos do curso de Letras segundo porção média consumida dos grupos de}

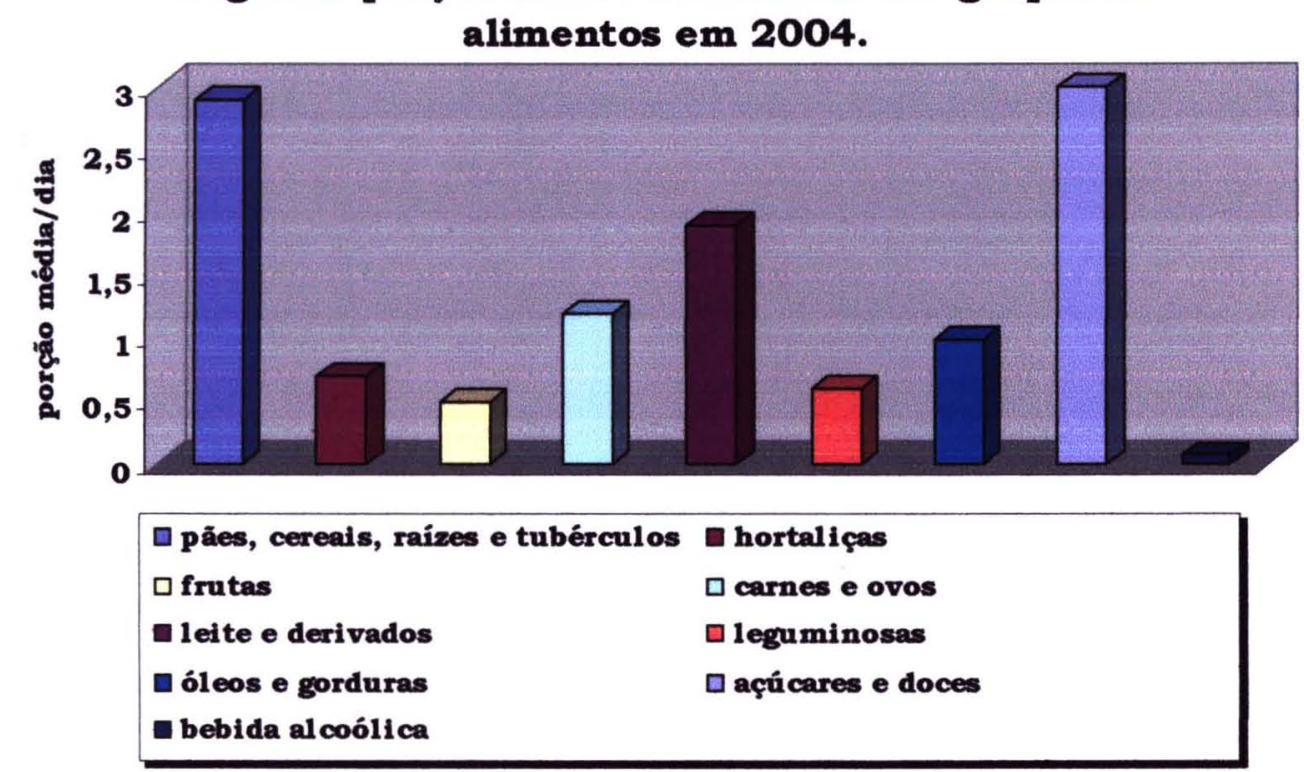




\subsection{Caracteristicas gerais, hábitos alimentares e estilo de vida}

De uma maneira geral, os alunos de ambos os cursos em 2003 apresentaram características semelhantes entre si, exceto para algumas variáveis: hábito de realizar o jantar (tabela 3), estado nutricional (tabela 5), média de pessoas residentes no domicílio, média de IMC e da idade (tabela 6).

Com relação à segunda avaliação, realizada em 2004, verificouse semelhanças entre os estudantes de ambos os cursos no que se refere a todas as variáveis estudadas. Porém, foram observadas diferenças estatisticamente significativas entre os alunos com relação à avaliação do estado nutricional (tabela 10).

A proporção de estudantes de ambos os cursos que realizavam desjejum aumentou em 3,8\%, ou seja, de 84,3\% em 2003 para $87,5 \%$ em 2004.

Em estudo realizado por VIEIRA e col. (2002) com 185 adolescentes de diversos cursos de graduação de uma universidade pública brasileira, $57,3 \%$ omitiam uma das refeições principais. Tal resultado vai de encontro ao verificado na presente pesquisa em que informaram omitir uma das principais refeições, no caso o jantar, $42,9 \%$ e $16,3 \%$ dos alunos dos cursos de Letras e Nutrição respectivamente. Essas proporções mantiveram-se semelhantes na segunda avaliação $(38,5 \%$ e $14,8 \%)$.

Análise transversal de uma amostra proveniente do Bogalusa Heart Study 1988/91 realizado por NICKLAS e col. (1998) com 504 jovens (média de idade $=23$ anos; $58 \%$ mulheres), concluiram que $37 \%$ dos individuos omitiram o desjejum. Dos que realizam o desjejum, $75 \%$ deles faziam essa refeição em casa, 10\% em lanchonetes, e 15\% 
em outros locais. Constataram ainda que alta proporção dos indivíduos que omitiram o café da manhã não conseguiram atingir $2 / 3$ das RDAs para as vitaminas e minerais estudados (vitaminas A, $\mathrm{B}_{6}, \mathrm{~B}_{12}, \mathrm{C}, \mathrm{D}, \mathrm{E}$, niacina, tiamina, riboflavina, folacina, magnésio, ferro, zinco, fósforo, cálcio e potássio).

Conforme se nota na tabela 4, em 2003, 76,47\% dos estudantes do curso de Nutrição e 69,2\% dos alunos do curso de realizavam as principais refeições (café da manhã, almoço e jantar) no próprio domicílio. Lanches intermediários (manhã e tarde) eram realizados por $53 \%$ dos alunos do curso de Nutrição e $47 \%$ dos alunos do curso de Letras fora de casa: faculdade e local de trabalho (tabela 4). Em 2004, os resultados mantiveram-se inalterados, segundo tabela 9 .

Dados de três estudos populacionais americanos sobre consumo alimentar, com 16810 individuos na faixa etária entre 1218 anos (adolescentes) e 19-29 anos (adultos jovens) mostraram que ambos os grupos populacionais estudados, no decorrer dos anos, passaram a apresentar uma dieta com valor calórico total menor no domicílio e maior em restaurantes e lanchonetes. Além disso, verificou-se também um aumento no consumo de pizzas e lanches, e uma diminuição no consumo de sobremesas, produtos lácteos e produtos a base de carnes, em ambos os grupos etários (NIELSEN e col. 2002).

A não prática de exercícios físicos foi afirmativa por $50 \%$ dos alunos do curso de Nutrição e $47,6 \%$ pelos alunos do curso de Letras na avaliação de 2003. Em 2004, detectou-se elevação na proporção de alunos sedentários, tendo sido observado $69,2 \%$ para os alunos do curso de Letras e $51,9 \%$ para os alunos do curso de Nutrição. Esses resultados mostraram-se consistentes com aqueles verificados por 
VIEIRA e col. (2002), onde $57 \%$ dos estudantes entrevistados não realizavam atividade fisica.

Deve ser mencionado que o sedentarismo está sendo frequentemente apontado como uma das causas no aumento das taxas de sobrepeso e obesidade em populações de diversos paises (WHO 2003).

\subsection{Estado Nutricional}

Ainda que em 2003, 66\% dos estudantes apresentavam estado nutricional considerado normal, detectou-se $21,6 \%$ de alunos com excesso de peso, ocorrendo em maior proporção de alunos do curso de Letras (tabela 5). Em 2004, 15\% dos alunos estudados foram diagnosticados com excesso de peso, sendo a maior proporção entre os alunos de Letras (tabela 10), com diferença estatisticamente significativa entre os alunos dos cursos, em ambos os períodos de avaliação. Porém deve ser considerado que a perda de amostra entre os alunos de Letras entre os anos de 2003 e 2004 (de 21 para 14 alunos), o que consequentemente pode ter influenciado os resultados encontrados.

Conforme mencionado, esta IPES mantém serviço ambulatorial de Nutrição desde 2001, para toda comunidade interna e externa. Esse serviço foi divulgado desde o início da pesquisa para os alunos dos cursos de Nutrição e Letras. Porém os que mais freqüentaram este ambulatório foram os alunos do curso de Nutrição. Apenas 2 alunos do curso de Letras procuraram o ambulatório, em 2004, após o término da coleta dos dados. 
Outros estudos longitudinais internacionais encontrados na literatura mostraram aumentos no peso corporal, em ambos os sexos, entre os periodos avaliados.

BALL e col (2002) ao analisarem dados de 8726 jovens australianas (18-23 anos) em um periodo de quatro anos encontraram na primeira avaliação proporção de jovens com sobrepeso e obesidade inferior aos verificados quatro anos depois. Concluiram que $44 \%$ das mulheres mantiveram seu peso durante os quatro anos de seguimento, enquanto que $41 \%$ ganharam peso e $15 \%$ das mulheres perderam peso. Constataram também que a manutenção de peso relacionou-se à categoria profissional ocupada, estado civil, estudar e não terem tido filhos. As jovens que mantiveram o peso corporal permaneciam menos tempo sentadas $\mathrm{e}$ consumiam menos refeições com alta densidade calórica (lanches) quando comparadas com aquelas com ganho de peso.

Dados de 8091 universitários e 2750 universitárias, na faixa etária entre 18 e 22 anos, do estudo longitudinal conduzido no Pais de Gales, mostraram que houve uma tendência secular no aumento do IMC para os jovens do sexo masculino entre 1950 e 1960, para o sexo feminino houve uma tendência à diminuição do IMC médio, mas não houve mudanças na proporção das jovens com sobrepeso, o que pode ser explicado pelo aumento dos transtornos alimentares que ocorre mais em mulheres do que em homens (OKASHA e col. 2003).

SHEEHAN e col. (2003) avaliaram 5117 individuos na faixa etária entre 25 e 74 anos (no inicio do estudo), durante um periodo de 20 anos, tendo observado que as mulheres mais jovens, ganharam 7,7 quilos (ou $0,39 \mathrm{~kg} / \mathrm{ano}$ ), e que param de ganhar $\mathrm{e}$ começam a perder peso por volta dos 60 anos. Concluíram ser necessário meio efetivo de prevenção da obesidade em individuos 
mais jovens, uma vez que muitos norte americanos apresentam-se obesos por volta dos 25 anos.

Resultados de estudos transversais mostram altas taxas de sobrepeso e obesidade entre a população jovem.

HUANG e col. (2003) realizaram um estudo com 736 estudantes universitários americanos, na faixa etária entre 18 e 27 anos, verificando $21,6 \%$ desses estudantes com sobrepeso e $4,9 \%$ com obesidade (IMC $\geq 30 \mathrm{~kg} / \mathrm{m}^{2}$ ).

No estudo realizado por VIEIRA e col. (2002) a proporção de alunos diagnosticados com sobrepeso foi de $4,8 \%$, número inferior ao encontrado neste estudo para os cursos de Nutrição e Letras (tabelas 5 e 10).

Dados de uma pesquisa realizada em 1995 com 4609 estudantes de graduação ( $\geq 18$ anos) dos Estados Unidos, detectaram $35 \%$ com sobrepeso ou obesidade (IMC $\geq 25 \mathrm{~kg} / \mathrm{m}^{2}$ ). Além disso, foi verificado que $54 \%$ das jovens do sexo feminino e $41 \%$ do sexo masculino utilizavam exercícios físicos e dieta para o controle de peso (LOWRY e col. 2000).

BERTSIAS e col. (2003), em pesquisa realizada com 989 estudantes universitários gregos do curso de medicina, encontraram maior proporção de alunos do sexo masculino com excesso de peso, quando comparados com estudantes do sexo feminino. Além disso, grande proporção deles apresentou associação com hipertensão arterial e dislipidemias.

Foi conduzido estudo para avaliar risco de doenças cardiovasculares entre 88 estudantes norte americanos de um curso 
de medicina e foi encontrado maior proporção de indivíduos do sexo masculino com sobrepeso. Os resultados do inquérito alimentar mostraram maior quantidade de lipídios nas dietas dos alunos do sexo masculino (SNETSELAAR e col. 2003).

A prevalência de sobrepeso e obesidade vem aumentando ano a ano, tanto em países desenvolvidos como nos paises em desenvolvimento, como o caso do Brasil. Vários fatores estão envolvidos na gênese do sobrepeso e obesidade: vida sedentária, consumo de dieta com alta densidade calórica, além de fatores genéticos, metabólicos, psicossocias, entre outros, que atuam na origem e na manutenção da obesidade (CARVALHO 2002).

De acordo com dados dos três principais inquéritos nacionais realizados em 1974/75 (Estudo Nacional da Despesa Familiar ENDEF), 1989 (Pesquisa Nacional sobre Saúde e Nutrição - PNSN) e 1997 (Pesquisa Sobre Padrōes de Vida - PPV, realizada no Sudeste e Nordeste), cumulativamente, a prevalência do sobrepeso (IMC entre 25 e $29,9 \mathrm{~kg} / \mathrm{m}^{2}$ ) e obesidade entre mulheres adulta aumentou de $22,2 \%$ encontrada no primeiro inquérito para $39,1 \%$ no segundo e para $47 \%$ no terceiro inquérito, com um aumento total de $112 \%$ (BATISTA FILHO e RISSIN 2003).

Estudos realizados na Europa, com a população jovem, entre 15 e 24 anos, mostram que a prevalência de obesidade vem aumentando, apesar da diminuição no consumo total de energia e gordura, mas com uma redução da atividade física, o que está diretamente relacionado com o gasto energético (MARTINEZ 2000).

Dados da Organização Mundial da Saúde (1998) mostraram que $54 \%$ dos indivíduos adultos nos Estados Unidos estão com 
sobrepeso (IMC $\geq 25 \mathrm{~kg} / \mathrm{m}^{2}$ ) e $22 \%$ estão obesos (IMC $\geq 30$ ) (PEREIRA e col. 2003).

Diferentemente das pesquisas anteriores estudo conduzido com 650 estudantes alemães (288 homens e 362 mulheres), na faixa etária entre 19 e 33 anos, de diversos cursos de graduação encontraram apenas $6,5 \%$ de estudantes com excesso de peso, sendo 43,5\%relataram grande empenho em realizar alimentação saudável, $53,2 \%$ informaram consumir uma alimentação com baixa quantidade e $28,5 \%$ mostraram interesse em ter na universidade um programa voltado para saúde e nutrição (STOCK e col. 2001).

ANTA e col. (1997) ao realizarem um estudo com 91 universitárias espanholas de 20 e 32 anos de idade encontraram somente $5,5 \%$ delas com sobrepeso. Os autores concluiram baixa prevalência na subestimativa no consumo do valor calórico total e que esse fato poderia estar relacionado com a baixa prevalência de obesidade, além das estudantes pertenceram à área da saúde e terem sido motivadas para participar do estudo adequadamente.

O fato dos alunos do curso de Nutrição terem apresentado um estado nutricional melhor quando comparados com os do curso de Letras em ambos os periodos de avaliação (tabelas 5 e 10) pode estar relacionado com os motivos que definiram sua escolha profissional, denotando uma possível preocupação maior com a saúde e a qualidade de vida. No sentido de conhecer esses motivos, encontraram -se dois relatos:

"Pois já fiz muitas dietas e sei a dificuldade que é para se conseguir emagrecer e pretendo ajudar as pessoas com essa dificuldade..."

"Fui obesa na infância...." 
Tais descrições indicam a preocupação com o peso corporal que vai ao encontro do observado por NAIVA e col (2003) que verificaram entre os egressos de um curso de Nutrição grande preocupação com esse assunto. No entanto, não encontraram diferenças nos hábitos alimentares e no conhecimento sobre nutrição entre aqueles estudantes que desejavam perder peso e os demais.

Já os motivos que levaram os alunos do curso de Letras a escolherem o curso, não tiveram qualquer relação com saúde e bem estar.

\subsection{Consumo alimentar}

No presente estudo, o perfil do consumo de alimentar médio dos estudantes dos cursos de Nutrição e Letras apresentaram-se de forma semelhante.

Considerando a distribuição dos macronutrientes em relação ao valor calórico total, verificou-se que em 2003 as proporções de lipídios mostraram-se superiores tanto para os alunos do curso de Nutrição quanto para os alunos do curso de Letras (tabela 6) em relação ao valor máximo recomendado pela WHO (2003) (hidratos de carbono: 55 a $75 \%$; proteinas: 10 a $15 \%$; lipídios: 15 a $30 \%$ ). No segundo periodo de avaliação (2004), esta situação mostrou-se semelhante, conforme resultados apresentados na tabela 11. Sabe-se que uma dieta balanceada é de fundamental importância para a manutenção do peso corporal, bem como para a prevenção de doenças crônicas não transmissíveis (diabetes tipo 2, hipertensão arterial, dislipidemias, obesidade) (WHO 2003).

Quanto aos valores calóricos totais médios das dietas em 2003, tanto para os estudantes do curso de Nutrição $(1864,77$ calorias e 
desvio padrão de 798,45 calorias), quanto para os de Letras $(2038,06$ calorias e desvio padrão de 972,96 calorias) apresentaram-se abaixo do valor recomendado quando comparados com aqueles preconizados para a população norte americana (RDA - Recommended Dietary Allowances) considerando-se como padrão, um indivíduo jovem sadio com atividade fisica leve (NRC 1989). O mesmo pode ser dito com relação à segunda avaliação (tabela 11).

Estes resultados são consistentes com a análise proveniente de uma amostra do estudo americano National Health and Nutrition Examination Survey (NHANES III/1985-91) com 838 estudantes universitárias na faixa etária entre 20 e 29 anos, onde foi verificado que a ingestão média diária de calorias foi de 1957 calorias, sendo $34 \%$ do valor calórico total (VCT) provenientes dos lipídios, $50 \%$ dos hidratos de carbono e $16 \%$ de proteínas.

A elevada proporção de lipídios na dieta também foi encontrada em estudo realizado por SONG e col. (1996), com 2489 estudantes universitários norte americanos, na faixa etária entre $18 \mathrm{e}$ 24 anos, de cursos relacionados à área da saúde, incluindo nutrição. Verificaram ala proporção de lipídios e baixa proporção de carboidratos em relação ao VCT. Porém, os valores médios para diversos micronutrientes atingiram a recomendação preconizada para a população americana (RDA-1989).

$\mathrm{Na}$ análise dos estudos populacionais americanos em três décadas diferentes sobre consumo alimentar, conduzida por (NIELSEN e col. 2002) verificou-se um aumento na média do valor calórico das dietas tanto dos adolescentes quando dos adultos jovens. Os responsáveis por estes aumentos foram os lanches no caso dos adolescentes e os lanches juntamente com as refeições para os adultos jovens. 
Um dos fatores que pode levar o individuo a apresentar sobrepeso ou obesidade, não é somente o valor calórico total da dieta, mas também o total de lipidios consumido. Os lipídios aumentam a densidade energética, além de apresentar baixa prioridade na oxidação, e estar associado à baixa saciedade do indivíduo. Portanto, a substituição dos lipídios da dieta por outro macronutriente está diretamente relacionada à diminuição da densidade energética da mesma, podendo levar à diminuição dos índices de obesidade. No entanto, a substituição dos lipídios também tem sido relacionada à compensação do valor calórico da dieta por outros nutrientes, principalmente carboidratos (ROSADO e MONTEIRO 2001).

FREGAPANE e ASENSIO-GARCÍA (2000) realizaram estudo com 205 universitários espanhóis, tendo sido verificado que $95 \%$ dos individuos consumiam dieta com baixa proporção de carboidratos, $90 \%$ dos participantes mostraram um consumo excessivo de sacarose (um dos carboidratos simples), maior do que $10 \%$ em relação ao valor calórico total e $95 \%$ dos estudantes relataram consumo excessivo de gorduras (mais do que $30 \%$ em relação ao valor calórico total).

Estudo internacional sobre crenças e comportamentos em saúde (incluindo hábitos alimentares) realizado em 21 países da Europa, com mais de 16.000 estudantes universitários (excluidos aqueles de cursos das áreas da saúde), com idade média de 21,3 anos, mostrou que houve baixa prevalência de práticas dietéticas saudáveis entre a população estudada, em média $29 \%$ dos jovens do sexo masculino e $49 \%$ das jovens tentaram evitar consumo de gorduras; $32 \%$ dos individuos do sexo masculino e $50 \%$ do sexo feminino tentaram consumir fibras; $43 \%$ dos jovens do sexo masculino e $62 \%$ das jovens consumiam frutas diariamente, $46 \%$ dos jovens do sexo masculino e $62 \%$ das jovens limitaram a ingestão de 
carne vermelha; $69 \%$ dos individuos do sexo masculino e $68 \%$ do sexo feminino limitaram o consumo de sal (WARDLE e col. 1997).

Um outro estudo realizado em 13 paises europeus, com 20776 estudantes universitários de cursos não relacionados à área da saúde, mostrou que ao serem comparados com resultados obtidos em outra encontrou que em dez anos houve diminuição no consumo diário de frutas, $24 \%$ dos indivíduos do sexo masculino e $46 \%$ do sexo feminino informaram limitar o consumo de lipídios e, dez anos antes, $27 \%$ e $46 \%$ dos individuos do sexo masculino e feminino respectivamente tiveram a mesma proporção (STEPTOE e col. 2002).

GEORGIOU e col. (1997) realizaram estudo com 758 jovens norte americanos do sexo feminino e 580 do sexo masculino, na faixa etária entre 18 e 24 anos, que encontravam-se cursando a graduação, graduados e aqueles que não faziam curso superior. Foi diagnosticada maior prevalência de sobrepeso entre as jovens que não cursavam nenhum curso de graduação.Além disso, os estudantes de graduação e os graduados consumiram maior quantidade de cereais ricos em fibras, de frutas e verduras verdes escuras, de leite desnatado e de carne do que os não estudantes. Concluiram que os individuos não estudantes apresentaram maior risco para algumas doenças em função de seus hábitos alimentares e escolhas alimentares inadequados, do que os estudantes de graduação e os graduados.

RABELO e col. (1999) em pesquisa com 209 estudantes brasileiros, entre 17 e 25 anos, detectaram vida sedentária, excesso no consumo de gordura total e de colesterol, tabagismo, hipertensão, sobrepeso e obesidade como os principais fatores de risco. 
Estudo realizado com 1912 alunos norte americanos (607 do sexo masculino e 1305 do sexo feminino) matriculados no curso de nutrição, com idade entre 19 e 20 anos, mostrou que $20,3 \%$ dos alunos do sexo masculino e $21,5 \%$ do sexo feminino omitiam o café da manhã. Além disso, dos 40 alimentos consumidos com maior freqüencia encontravam-se as bebidas carbonatadas, e em menor freqüència frutas $\mathrm{e}$ hortaliças. Alimentos muito gordurosos apareceram em menor freqüência quando comparados com aqueles com menor quantidade de gordura (frango, peru, leite desnatado ou semi-desnatado). Porém, os alunos do sexo masculino apresentaram dietas com maior quantidade de calorias, maior quantidade de alimentos ricos em gorduras e pequena quantidade de hortaliças, quando comparados com as alunas (HUANG e col. 1994).

Estudo realizado por ZIZZA e col. (2001) mostrou que o consumo de lanches aumentou de 77 para $84 \%$ em 20 anos. A contribuição energética das sobremesas com elevada quantidade de lipídios para o total de calorias dos lanches diminuiu (22 para 14\%), porém este grupo de alimentos permaneceu a principal fonte de energia. A contribuição energética dos lanches salgados ricos em gorduras dobrou. As bebidas adoçadas e alcoólicas permaneceram como importantes contribuintes no valor calórico total.

Diferentemente do estudo anterior, no presente estudo, as bebidas alcoólicas não tiveram consumo elevado para os cursos estudados, nos dois períodos de avaliação (gráficos 1 e 2). O mesmo ocorreu para o consumo de sanduíches com alta densidade calórica , pizza e salgados, com baixo consumo entre todos os alunos e nos dois periodos de avaliação.

$\mathrm{Na}$ presente pesquisa, o consumo de açúcares e doces (incluindo refrigerante e sucos em pó), apresentou-se superior ao 
número de porções recomendadas.Cabe lembrar que independentemente destes tipos de bebidas possuirem maior ou menor quantidade de açúcar, não contribuem com nenhum nutriente importante para alimentação.

Um estudo de coorte desenvolvido na Noruega, com individuos de 14 anos (início) e 21 anos (no término do estudo), encontrou que a freqüência média semanal de frutas e hortaliças diminuiu de 1-2,5 vezes na semana, enquanto o consumo de bebidas não alcoólicas adoçadas aumentou em 1 vez por semana (LIEN e col. 2001).

WHICHELOW e PREVOST (1996) verificaram que o consumo freqüente de alimentos ricos em gordura foi predominantemente maior na população mais jovem.

Ao contrário dos estudos citados anteriormente mostrando que estudantes universitários apresentam consumo e hábitos alimentares incorretos, outras pesquisas apresentam resultados mais favoráveis para esta população.

MONNEUSE e col. (1997) realizaram um estudo com 292 estudantes franceses do sexo masculino e 365 do sexo feminino (com média de 21 anos de idade) encontrando comportamentos alimentares "saudáveis" que foram relatados pela maioria dos estudantes, tais como, evitar o consumo de gorduras e colesterol, esforços para o consumo de frutas e fibras e que mantinham o saudável hábito de realizar o café da manhã.

No presente estudo, o valor médio encontrado para os micronutrientes causa certa preocupação. 
$\mathrm{Na}$ primeira avaliação realizada em 2003, para o cálcio, o valor médio encontrado atingiu valores abaixo da ingestão adequada para a população norte americana tanto para o curso de Nutrição quanto para o curso de Letras, considerando a faixa de ingestão adequada para individuos na faixa etária entre 19 e 50 anos, para ambos os sexos (TRUMBO e col. 2002). Em 2004, a situação não foi diferente para ambos os cursos.

No estudo conduzido por FREGAPANE e ASENSIO-GARCÍA (2000), mais de 50\% dos estudantes universitários entrevistados relataram um consumo de cálcio menor do que $800 \mathrm{mg} / \mathrm{dia}$, demonstrando um baixo consumo de leite e derivados.

O consumo de cálcio insuficiente por um periodo de tempo é uma das principais causas de problemas ósseos como a osteoporose (definida como uma "doença metabólica óssea sistêmica, caracterizada por diminuição da massa óssea e deterioração da microarquitetura do tecido ósseo, com conseqüente aumento da fragilidade do osso e da suscetibilidade a fraturas") e a osteopenia ("diminuição da massa óssea porém sem comprometimento da microarquitetura") os quais são problemas crescentes no Brasil e em outros paises preocupando a área de saúde pública (CAMPOS e col. 2003).

A osteopenia e a osteoporose deixaram de ser uma preocupação exclusiva de indivíduos adultos e idosos, já que a densidade mineral óssea nestas faixa etárias depende do pico de massa óssea adquirido até o final da segunda década de vida (Van Der Sluis e Muinck Keizer-Schrama 2001). 
$\mathrm{Na}$ presente pesquisa o baixo consumo de cálcio encontrado para ambos os cursos deveu-se principalmente a falta no consumo de leite e derivados, principais fontes deste nutriente na dieta..

Ressalta-se que tal observação vai ao encontro do verificado em outros estudos.

Em pesquisa realizada por WHAM e WORSLEY (2002) na Nova Zelândia, com 719 indivíduos na faixa etária entre 16 e 65 anos, foi observado maior ausência no consumo de leite e derivados entre as mulheres jovens. Constataram também que $90 \%$ dos individuos desconheciam a qualidade nutricional do leite. Ainda que a maioria dos entrevistados acreditasse que o "leite é melhor do que os refrigerantes", $25 \%$ da população jovem não compartilhou desta mesma opinião. Concluíram que o baixo consumo de leite é um problema sério relacionado ao estado nutricional dos individuos, principalmente para as mulheres jovens.

Os estudos de SONG e col (1996) e HENDRICKS e HERBOLD (1998) também encontraram consumo de cálcio abaixo dos valores de recomendação na população estudada.

A exemplo do cálcio, também não atingiu os valores recomendados para a população norte americana (TRUMBO e col, 2002) em 2003 (tabela 6). Tais resultados mantiveram-se abaixo do valor recomendado na segunda avaliação (2004), no entanto, com valor relativo superior entre os estudantes do curso de Letras $\mathrm{e}$ inferior para os estudantes do curso de Nutrição (tabela 11).

Como é sabido, o consumo insuficiente de ferro dietético pode ter como decorrência a provável instalação da anemia ferropriva, definida por uma diminuição na concentração de hemoglobina no 
sangue, caracterizada por sintomas como fraqueza, diminuição da capacidade respiratória e tonturas, que é um problema de saúde pública apresentando prevalência que atinge elevada proporção especialmente entre crianças e adolescentes. Mesmo na ausência de anemia, a deficiência de ferro pode provocar distúrbios neurocognitivos (PAIVA e col 2000). Na gravidez, a deficiência de ferro aumenta a morbidade materna, incluindo trabalho de parto prematuro e feto de baixo peso ao nascimento (CHANARIM 2003).

Estudo realizado por BRENER e col (2003), com 30 alunas do $4^{0}$ periodo do curso de Nutrição de uma universidade pública do Rio de Janeiro, encontraram que as dietas eram hiperprotéicas, além de valor relativo elevado de lipidios na dieta de final de semana. Foi verificado também um alto percentual de alunas com ingestão de cálcio, ferro e vitamina A inferior a $67 \%$ das recomendações norte americanas. Concluiu-se que, tal comportamento alimentar pode influenciar negativamente o estado nutricional destas universitárias.

Considerando o que foi discutido até o momento, pode ser observado que os erros no consumo alimentar não são privilégios somente dos alunos do curso de Letras, mas também dos alunos do curso de Nutrição, ainda que esses recebam maior quantidade de informações sobre alimentação, nutrição e saúde diariamente, diferentemente dos alunos do curso de Letras. Porém, um grande número de informações sobre nutrição e saúde é divulgado atualmente nos meios de comunicação de massa atingindo grande parcela da população As revistas não científicas muitas vezes divulgam informações sobre saúde e nutrição erradas, como, por exemplo, as dietas de emagrecimentos "milagrosas", influenciando de maneira negativa os leitores que, na maioria das vezes, são leigos no assunto. 
SANTOS e BARROS FILHO (2002) realizaram estudo com 894 ingressantes brasileiros das áreas de exatas, humanas e biológicas de uma universidade particular. Os profissionais que se destacaram pela confiablidade das informaçōes sobre alimentação e nutrição foram médicos e nutricionistas.

Em relação à esta pesquisa, por se tratar de estudantes universitários, acreditava-se em resultados mais favoráveis.

Esperava-se mudanças no comportamento alimentar dos estudantes do curso de Nutrição ao longo de um ano, fato não observado no estudo. Os resultados encontrados neste estudo são conflitantes com os verificados em outras pesquisas.

Estudo realizado por VIEIROS e col. (2003), em uma universidade de Santa Catarina, com 35 estudantes universitários do $1^{\circ}$ periodo e 39 do $5^{\circ}$ periodo, do Curso de Nutrição, mostrou que a partir do diagnóstico nutricional realizado pelo IMC, no $1^{\circ}$ periodo, $25,8 \%$ dos estudantes apresentaram desnutrição e 74,19\% eram eutróficos. No $5^{\circ}$ periodo $2,57 \%$ dos estudantes apresentaram desnutrição e $43 \%$ foram diagnosticados como eutróficos. Os autores sugeriram que apesar das modificações que ocorrem na vida do estudante ao ingressar na universidade, o conhecimento adquirido no decorrer do curso sobre a importancia e os beneficios de uma alimentação nutricionalmente adequada, seu impacto na saúde e na qualidade de vida, podem influenciar positivamente a adoção de comportamentos alimentares e hábitos de vida saudáveis, pelos acadêmicos do curso de Nutrição.

DIAS e col. (2003) realizaram uma pesquisa em uma faculdade em Vitória, com 115 alunos, matriculados em um curso de Nutrição e os resultados mostraram que houve mudança nos hábitos 
alimentares, desde o primeiro periodo, com o número de refeições e diminuição no consumo de doces. No entanto, segundo os entrevistados, as mudanças mais significantes foram percebidas a partir do terceiro periodo. Foi sugerido pelos autores que essas mudanças podem estar relacionadas com o início do estudo da composição dos alimentos.

Estudo longitudinal prospectivo, multicèntrico que investigou a evolução dos fatores de risco para doenças cardiovasculares, realizado com 3726 jovens norte americanos na faixa etária entre 18 e 30 anos no inicio do estudo (1985/86, encontrou no final do estudo (1993), maior número de mudanças no consumo alimentar foi observado entre aqueles que possuiam alto grau de escolaridade $(\geq 12$ anos). Houve uma significante diminuição na proporção de gordura saturada e colesterol e um significante na proporção de carboidratos complexos (ARCHER e col. 2003).

Após a discussão realizada anteriormente acerca dos dados encontrados nesta pesquisa comparados com outros resultados tanto de estudos nacionais quanto internacionais, deve ser mencionado que a presente pesquisa apresenta algumas limitações, amostras com número pequeno e curto tempo de seguimento. Porém, apesar disso, houve a possibilidade de se fazer comparações entre os dois grupos populacionais estudados utilizando-se testes estatísticos não paramétricos, que são especificos para amostras pequenas. Além disso, estudos populacionais com longos periodos de seguimento, possuem alto custo e tornam-se, portanto muitas vezes inviáveis de serem realizados, devido a dificuldades na adesão por parte dos participantes. 
6. CONSIDERAÇÕES FINAIS 
Com relação ao estado nutricional dos alunos de acordo com o IMC, verificou-se que a maior parte dos alunos tanto do curso de Nutrição como do curso de Letras encontrava-se na faixa de normalidade em 2003 e em 2004 em relação ao estado nutricional. Porém, um maior número de alunos do curso de Letras apresentouse com excesso de peso nos 2 periodos de avaliação.

O valor calórico da dieta, para ambos os cursos, encontrou-se abaixo dos valores de recomendação preconizados para a população norte americana em 2003 e em 2004.

O consumo médio dos macronutrientes (carboidratos, lipidios e proteínas) em relação ao valor calórico total (VCT) apresentou-se dentro das faixas de recomendação nos periodos de avaliação, com exceção dos lipídios, que excedeu os valores recomendados em 2003 e em 2004.

O consumo médio de cálcio e ferro para os alunos do curso de Nutrição e para os do curso de Letras não atingiu os valores recomendados tanto em 2003 quanto em 2004.

No que se refere ao consumo de alimentos, os alunos dos cursos de Nutrição e Letras não alcançaram os números de porções recomendadas pela pirâmide alimentar adaptada para os grupos de pães/cereais/raizes e tubérculos, hortaliças, frutas, leguminosas e leite/derivados, mas consumiram acima dos valores recomendados para os grupos de carnes/ovos e açúcares/doces, em ambos os periodos de avaliação.

As mudanças ocorridas entre 2003 e 2004 para "hábito de fazer dieta modificada nos últimos 6 meses, uso de suplemento alimentar, hábito de realizar as principais refeições (desjejum, almoço 
e jantar) e as refeições intermediárias (lanche da manhã, lanche da tarde e ceia)" para ambos os alunos dos cursos não foram estatisticamente significativas.

As mudanças ocorridas no "consumo médio dos macronutrientes em relação ao valor calórico total, cálcio, ferro, consumo de água e IMC médio intra curso (Nutrição X Nutrição, Letras X Letras) e entre os cursos (Nutrição $X$ Letras) nos periodos avaliados, também não foram estatisticamente significativas.

A hipótese inicial de que os alunos dos cursos de Nutrição e Letras seriam semelhantes em 2003 e, que em 2004 ocorreriam mudanças positivas referentes ao consumo alimentar para o curso de Nutrição, e que os cursos de Nutrição e Letras comportar-se-iam de forma totalmente diferente em 2004, não foi verificada. Porém, deve ser ressaltado que os alunos do curso de Letras no início e no término do estudo apresentaram-se em maior proporção com excesso de peso, com diferenças estatisticamente significativas quando comparadas com os alunos do curso de Nutrição. 
7. REFERÊNCIAS 
Anta RMO, Herrero EQ, Quiles BS, Carvajales PA, Marcos AMR, Sotillos $\mathrm{AE}$. Infravaloración de la ingesta energética em um colectivo de jóvenes universitárias de Madrid. Rev Clin Esp 1997; 197: 54549.

Archer SL, Hilne JE, Dyer AR, Greenlund KJ, Colangelo LA, Kiefe CI, Liu K. Association of education with dietary intake among young adults in the bi-ethnic Coronary Artery Risk Development in young adults (CARDIA) cohort. Publ Health Nutr 2003; 6: 689-95.

Baeninger R. Demografia da população jovem. In: Shor N, Mota $M$, Castelo Branco V, organizadores. Cadernos Juventude, Saúde e Desenvolvimento. Brasilia (DF); Ministério da Saúde 1999. v.1, p. 19-29.

Ball K, Brown W, Crawford D. Who does not gain weight? Prevalence and predictors of weight maintenance in young women. Int $\mathbf{J}$ Obs Relat Metab Disord 2002; 26: 1570-8.

Bartrina JA. Educación nutricional. In Majem LS, Bartrina JA, Verdú JM. Nutrición y salud pública: métodos, bases cientificas y aplicaciones. Barcelona: Masson; 1995. p.334-42.

Batista Filho M, Rissin A. A transição nutricional no Brasil: tendências regionais e temporais. Cad Saúde Pública 2003; 19 suppl 1: S181-91.

Benevenuto L.C, Roque VS, Rodrigues GP, Neto HN, Praça JL. Avaliação da ingestão alimentar de estudantes do cursos de nutrição da Universidade de Uberaba. In: Programa Oficial do $2^{\circ}$ Congresso Internacional de Nutrição, Alimentação e Tecnologia, 2001 out. 04-06, São Paulo, Brasil. 
Bertsias G, Mammas I, Linardakis M, Kafatos I. Overweight and obesity in relation to cardiovascular disease risk factors among medical students in Crete, Greece. BMC Public Health 2003; 3: 1-9.

Brener F, Lanzilloti HS, Portella ES, Soares EA. O consumo alimentar de universitárias do curso de graduação em nutrição é adequado? In: Anasi do $7^{\circ}$ Congresso Nacional da Sociedade Brasileira de Alimentação e Nutrição; 2003; Belo Horizonte. p.90.

Camarano AA, Pazinato MT, Kanso S, Vianna C. A transição para a vida adulta: novos ou velhos desafios? [on line]. Brasília (DF):IPEA; 2003. Disponivel em $<$ URL: http://www.ipea.gov.br/pub/bcmt/mt_02j.pdff > [2004 Ago 11].

Campos LMA, Liphaus BL, Silva CAA, Pereira RMR. Osteoporose na infância e na adolescència. J Pediatr 2003; 79: 481-8.

Carvalho KMB. Obesidade. In: Cuppari L, coordenadora. Guia de Nutrição: nutrição clinica no adulto - guias de medicina ambulatorial e hospitalar UNIFESP/Escola Paulista de Medicina. Barueri: Manole; 2002. p. 131-65.(UNIFESP- EP Guias de Medicina Ambulatorial e Hospitalar).

Catani AM. O ensino superior no Brasil: perspectivas. In: Catani e col. Educação em debate. São Paulo: Moderna; 1998. p.121-41.

Chanarim I. Aspectos nutricionais das doenças hematológicas. In: Shils e col., editores. Tratado de nutrição moderna na saúde e na doença. 9a ed. São Paulo: Manole; 2003. p. 1519-41. v.2. 
Coppini LZ, Bottoni A, Silva MLT, Waitzberg DL. Aplicação da análise da impedância bioelétrica na avaliação nutricional. Rev Bras Nutr Clin 1998; 13: 81-9.

DeHoog S. Avaliação do estado nutricional. In Mahan LK, EscottStump S. Krause: alimentos, nutrição e dietoterapia. 9a ed. São Paulo: Roca; 1998. p.371-95.

Dias RR, Magevski M, Reginatto EM, Saraiva MN, Molina MCB. Mudanças nos hábitos alimentares dos alunos do curso de nutrição da Faculdade Salesiana de Vitória. In: Anais do $7^{0}$ Congresso Nacional da Sociedade Brasileira de Alimentação e Nutrição; 2003; Belo Horizonte. p.89.

Doria Filho U. Introdução à bioestatística para simples mortais. São Paulo: Elsevier; 2003.

Fiates GMR, Salles RK, Avancini SRP. Hábitos alimentares de estudantes universitários de diferentes áreas de conhecimento. In: Anais do $6^{\circ}$ Congresso Nacional da Sociedade Brasileira de Alimentação e Nutrição; 2001; Florianópolis. p.216.

Fisberg RM, Stella RH, Marimoto JM, Pasquali L.S, Philippi ST, Latorre MR. Perfil lipidico de estudantes de nutrição e a sua associação com fatores de risco para doenças cardiovasculares. Arq Bras Cardiol 2001; 76:137-42.

Focesi E. Uma revisão de saúde escolar e educação em saúde na escola. Rev Bras Saúde Esc 1992; 2: 19-21. 
Fregapane G, Asensio-Garcia C. Dietary assessment of an educated young Spanish population using a self-administered meal-based food frequency questionnaire. Eur J Epidemiol 2000; 16: 183-91.

Freire P. Pedagogia da autonomia. saberes necessários à pratica educativa. 23 ed. São Paulo: Paz e Terra; 2002. Não há docência sem discência; p. 38.

Gambardella AD. Adolescentes, estudantes de período noturno: como se alimentam e gastam suas energias. São Paulo; 1995. [Tese de Doutorado - Faculdade de Saúde Pública da USP].

Georgiou CC, Betts NM, Hoerr SL, Keim K, Peters PK, Stewart B, Voichick J. Among young adults, college students and graduates practiced more healthful habits and made more healthful food choices than did nonstudents. J Am Diet Assoc 1997; 97: 754-9.

Gibson RS. Principles of nutritional assessment. New York.: Oxford University Press; 1990.

Hendricks KM, Herbold NH. Diet, activity and other health-related behaviors in college-age women. Nutr Rev 1998; 56: 65-75.

Hertzler AA, Webb R, Frary RB. Over consumption of fat by college students: the fast food connection. Ecol Food Nutr 1995; 34: 49-57.

Huang Y, Song WO, Schemmel RA, Hoerr SM. What do college students eat? Food selection and meal pattern. Nutr Res 1994; 14: 1143-53. 
Huang TTK, Harris KJ, Lee RE, Nazir N, Born W, Kaur H. Assessing overweight, obesity and physical activity in college students. J Am Col Health 2003; 52(2): 83-6.

Iervolino SA. Escola promotora da saúde: um projeto de qualidade de vida. São Paulo; 2000. [Dissertação de Mestrado - Faculdade de Saúde Pública da USP].

Lien N, Lytle LA, Klepp K. Stability in consumption of fruit, vegetables, and sugary foods in a cohort from age 14 to age 21. Prev Med 2001; 33: 217-26.

López JV. Validez de la evaluación de la ingesta dietética. In: Majem LS, Bartrina JÁ, Verdú JM Nutrición y salud pública: métodos, bases científicas y aplicaciones. Barcelona: Masson; 1995. p. 1326.

Lowry R, Galuska DA, Fulton JE, Wechsler H, Kann L, Collins JL. Physical activity, food choice, and weight managements goals and practices among U.S. college students. Am J Prev Med 2000; 18: 1827.

Lukaski HC. Body mass index, bioelectrical impedance, and body composition. Nutrition 2001; 17: 55-6.

Majem LIS. Evaluación del consumo de alimentos en poblaciones. Encuestas alimentarias. In: Majem LS, Bartrina JA, Verdú JM. Nutrición y salud pública: métodos, bases científicas y aplicaciones. Barcelona: Masson; 1995. p. 90-106.

Martinez JA. Obesity in young Europeans: genetic and environmental influences. Eur J Clin Nutr 2000; 54 suppl 1: S56-60. 
Menchú LMT. Revision de las metodologias aplicadas en estudios sobre el consumo de alimentos. Guatemala: INCAP; 1992 (Publicación INCAP ME/015).

[MEC/INEP\}. Mistério da Educação e Cultura. Instituto Nacional de Estudos e Pesquisas Educacionais Anisio Teixeira.. Estatisticas básicas e indicadores da educação superior, por categoria administrativa - Brasil - 2002. Disponivel em < URL: http://www.ensinosuperior.inep.gov.br [2004 Ago 13]

Ministėrio da Saúde. Programa de Educação em Saúde [on line]. Brasilia (DF); 2000. Disponivel em<URL: http:// www.saude.gov.br/programas/pes/pes/progreduc.htm. [2000 Maio 3].

Ministério da Saúde. Anuário Estatistico de Saúde do Brasil 2001 [on line]. Disponivel em <URL: http://wwwportal.saude.gov.br/saude /aplicacoes/anuario2001 [2004 ago 18].

Monneuse MO, Bellisle F, Koppert G. Eating habits, food and health related attitudes and beliefs reported by French students. Eur $\mathbf{J}$ Clin Nutr 1997; 51: 46-53.

Monteiro CA. Velhos e novos males da saúde no Brasil. $2^{a}$ ed. São Paulo: NUPESN; 2000.

Motta DG, Boog MCF. Educação nutricional. 2a ed. São Paulo: IBRASA; 1988. 
[NRC] National Research Council. Recommended dietary allowances. 10 $10^{\text {th }}$ ed. Washington(DC): National Academy Press; 1989.

Navia B, Ortega RM, Requejo AM, Mena MC, Perea JM, López-Sobaler AM. Influence of the desire to lose weight on food habits, and knowledge of the characteristics of a balanced diet, in a group of Madrid university students. Eur J Clin Nutr 2003; 57 suppl 1: S9093.

Nicklas, TA, MyersL, Reger C, Beeh B, Berenson GS. Impact of breakfast consumption on nutritional adequacy of the diets of young adults in Bogalusa, Louisiana: ethnic and gender contrasts. J Am Diet Assoc 1998; 98: 1432-38.

Nielsen SJ, Siega-Riz AM, Popkins BM. Trends in food locations and sources among adolescents and young adults. Prev Med 2002; 35: 107-13.

Okasha M, McCarron P, Smith GD, Gunnell D. Trends in body mass index from 1948 to 1968: results from the Glasgow Alumni Cohort. Int $\mathbf{J}$ Obes Relat Metab Disord 2003; 27: 638-40.

Olivares S, Biolley E, Lerou I, Valiente S. Conocimientos alimentarios y nutricionales de alunos que ingresan a la Universidad de Chile. Rev Chil Nutr 1981; 9: 27-39.

Paiva AA, Rondó PHC, Guerra-Shinohara EM. Parâmetros para avaliação do estado nutricional de ferro. Rev Saúde Pública 2000; 34:421-6. 
Pereira LO, Francischi RP, Lancha Junior AH. Obesidade: hábitos nutricionais, sedentarismo e resistência à insulina. Arq Bras Endocrinol Metab 2003; 47: 111-27.

Philippi ST, Szarfarc SC, Latterza AR. Informatização em nutrição: virtual nutri- Versão 1.0 São Paulo: Depto. de Nutrição da FSP/USP; 1996. [Apresentado ao $4^{\circ}$ Congresso Nacional da Sociedade Brasileira de Alimentação e Nutrição; 1996; São Paulo].

Philippi ST, Latterza AR, Cruz ATR, Ribeiro LC. Pirâmide alimentar adaptada: guia para escolha dos alimentos. Rev Nutr 1999; 12: 6580.

Pinheiro ABV, Lacerda EMA, Benzecry EH, Gomes MCS, Costa VM. Tabela para avaliação de consumo alimentar em medidas caseiras. 3a ed. São Paulo: Atheneu; 1994.

Pinheiro ABV, Lacerda EMA, Benzecry EH, Gomes MCS, Costa VM. Tabela para avaliação de consumo alimentar em medidas caseiras. $5^{\text {a }}$ ed. São Paulo: Atheneu; 2004.

Prefeitura Municipal de Santos. Santos: cidade privilegiada. [on line] Disponivel em < URL: http//:www.santos.sp.gov.br. [2004 ago 14].

Quaioti TCB, Chaim RC, Franchischetti I, Utiyama M. Hábitos alimentares do $2^{\circ}$ e $8^{\circ}$ termos do curso de nutrição da Universidade do Sagrado Coração - Bauru - SP. Salusvita 1999; 18: 107-22. 
Rabelo LM, Viana RM, Schimith MA, Patin RV, Valverde MA, Denadai $\mathrm{RC}$, et al. Risk factors for atherosclerosis in studentes of a private university in São Paulo - Brazil. Arq Bras Cardiol 1999; 72: 57580.

Roncada M J, Mazzili R.N, Santos HS, Yun SK, Kato EA, Florentini AK Kawakami EH, Sabadin LM. Conhecimentos de nutrição como fator de mudança da dieta habitual. In: Anais do 20 Congresso Nacional da Sociedade Brasileira de Alimentação e Nutrição; 1990a; São Paulo. p. 241.

Roncada MJ, Mazzili RN, Santos HS, Yun SK, Kato EA, Florentini AK, Kawakami EH. Aspectos condicionantes do häbito alimentar de estudantes de nutrição. In: Anais do $2^{\circ}$ Congresso Nacional da Sociedade Brasileira de Alimentação e Nutrição; 1990b; São Paulo.São Paulo, p. 242.

Roncada MJ, Mazzili RN, Santos HS, Yun SK., Kato EA, Florentini AK Kawakami EH. Influência do conhecimento de nutrição na prática alimentar. In: Anais do $2^{\circ}$ Congresso Nacional da Sociedade Brasileira de Alimentação e Nutrição; 1990c; São Paulo. p. 243.

Rosado EL, Monteiro JBR. Obesidade e a substituição e de macronutrientes da dieta. Rev Nutr 2001; 14: 145-52.

Roubenoff $R$. Applications of bioelectrical impedance analysis for body composition to epidemiologic studies. Am J Clin Nutr 1996; 64 suppl: 459S-62S.

Santos KMO, Barros Filho AA. Fontes de informação sobre nutrição e saúde utilizadas por estudantes de uma universidade privada de São Paulo. Rev Nutr 2002; 15: 201-10. 
Sheehan TJ, DuBrava S, DeChello LM, Fang Z. Rates of weight change for black and white americans over a twenty year period. Int J Obes Relat Metab Disord 2003; 27: 498-504.

Schuette L.K, Song WO, Hoerr SL. Quantitative use of the food guide pyramid to evaluate dietary intake of college students. J Am Diet Assoc 1996; 96: 453-57.

Snetselaar LG, Malville-Shipan KL, Gordon JA. Cardiovascular risk factor self-assessment program: using the general clinical research center to provide a clinical experience for third-year medical students. J Nutr 2003; 133: 550S-55S.

Song WO, Schuette LK, Huang Y, Hoerr S. Food group intake patterns in relation to nutritional adequacy of young adults. J Am Diet Assoc 1996; 96: 1507-19.

Soriano JM, Moltó JC, Mañes J. Dietary intake and food pattern among university students. Nutr Res 2000; 20: 1249-58.

Steptoe A, Wardle J, Cui W, Belliske F, Ziotti AM, Baranyai R, Landerman $R$. Trends in smoking, diet, physical exercise and attitudes toward health in European University Students from 13 countries, 1990-2000. Prev Med 2002; 35: 97-104.

Stock C, Wille L, Krämer A. Gender-specific health behaviors of German university students predict the interest in campus health promotion. Health Promot Int 2001; 16: 145-54. 
Tam CF, Martinez E, Tsai S, Chang LC, Calderon L., Davis R, Yeh IA comparison of dietary atherogenicities, energy balance and physical activity levels of male and female college sudents. Nutr Res 1996;16: 1861-80.

Trumbo P, Schlicker S, Allison AY, Poos M. Dietary referente intakes for energy, carbohydrate, fiber, fat, fatty acids, colesterol, protein and amino acids. J Am Diet Assoc 2002; 102: 1621-30.

Van Der Sluis IM, Muinck Keizer-Schrama MPF. Osteoporosis in childhood bone density of children in health and disease. $\mathbf{J}$ Pediatr Endocrinol Metab 2001; 14: 817-32.

Veiros MB, Matos $\mathrm{CH}$. Comportamento alimentar e estilo de vida de acadêmicos do curso de nutrição de uma universidade fundacional de Santa Catarina. In: Anais do $7^{\circ}$ Congresso Nacional da Sociedade Brasileira de Alimentação e Nutrição; 2003; Belo Horizonte. p.89

Verdú JM, Marin EC. Nutrición para educadores. Madrid: Ediciones Diaz de Santos; 1995.

Verdú JM, Gonzaléz JL. Evaluación del estado nutricional. In: Majem LS, Bartrina JA, Verdú JM. Nutrición y salud pública: métodos, bases cinetificas y aplicaciones. Barcelona: Masson; 1995. p.73-89.

Vieira VCR, Priore SE, Ribeiro SMR, Franceschini SCC, Almeida LP. Perfil socioeconòmico, nutricional e de saúde de adolescentes recém ingressos em uma universidade pública brasileira. Rev Nutr 2002; 15(3): 273-82. 
Wardle J, Bellisle F, Reschke K, Steptoe A, Davou B, Lappalainen R, Fredrikson M. Healthy dietary practices among European students. Health Psychol 1997; 16: 443-50.

Wham CA, Worsley A. New Zealanders' attitudes to milk: implications for public health. Public Health Nutr 2002; 6: 73-8.

Wichelow M, Prevost AT. Dietary patterns and their associations with demographic, lifestyle and health variables in a random sample of British adults. Br J Nutr 1996; 76: 17-30.

Willett W. Nutritional epidemiology. 2ed. New York: Oxford University Press; 1998.

[WHO] World Health Organization. Physical status: the use and interpretation of anthropometry. Geneva; 1995. (WHO - Technical Report Series, 854).

[WHO] World Health Organization. Obesity: preventing and managing the global epidemic. Geneva; 2000. (WHO - Technical Report Series, 894).

[WHO] World Health Organization. Diet, nutrition and the prevention of chronic diseases. Geneva; 2003. (WHO - Technical Report Series, 916).

Ziwian ZLJ. Educação nutricional na adolescência. Hig Aliment 1999; $13: 85-7$. 
Zizza C, Siega-Riz AM, Popkin BM. Significant increase in young adults snacking between 1977-1978 and 1994 - 1996 represents a cause for concern. Prev Med 2001; 32: 303-10. 


\section{Universidade de São Paulo \\ Faculdade de Saúde Pública \\ Departamento de Nutrição}

Anexo 1 - Questionário; Caracteristicas gerais e hábitos alimentares

Nome: Sexo

Curso Série

Data de Nascimento:

Data:

\section{Prezado(a) aluno(a), por favor responda às questōes abaixo:}

1 - Explique qual(ais) motivo(s) o(a) levaram a escolher o Curso de Letras ? (pergunta feita somente em 2003)

2- Quantas pessoas moram na sua casa (incluindo voce) ?

3- Qual a renda familiar em salários mínimos (SM)? (Considerar todos que trabalham na sua casa):

< $3 \mathrm{SM}($ ) 3 a $5 \mathrm{SM}($ ) 5 a $7 \mathrm{SM}($ ) 7 a $9 \mathrm{SM}($ )

9 a $11 \mathrm{SM}()>11 \mathrm{SM}($ )

4- Fez algum tipo de dieta recentemente (últimos 6 meses) ou faz alguma dieta atualmente?

Sim ( ) não ( ) Que tipo de dieta?

Quem indicou essa dieta?

5 - Faz uso de suplemento/complemento alimentar? Sim（） Não（） Qual? Freqüència:

6-Assinale qual(ais) refeição(ções) voce faz por dia:

Café da manhã( ) lanche da manhã( ) almoço( )

Lanche da tarde ( ) jantar( ) ceia( )

Qual(ais) delas voce faz EM CASA?

Qual (ais) delas voce faz FORA DE CASA?

Onde?

7- Pratica atividade física? Sim( ) Não( ) Qual Freqüência

8- Voce bebe água diariamente? $\operatorname{Sim}($ ) não( )

Se sim, Quantos copos de água voce bebe por dia?

Obrigada pela colaboração!!!!!!!!!!!

Renata Doratioto Albano

Prof. do Curso de Nutrição

Doutoranda pela FSP/USP 
Anexo 2: Formulário para coleta de dados de peso e estatura

Curso:

Série

Data: _ I _ $/ 2003$

Série

Data: _ I__ / $/ 2004$

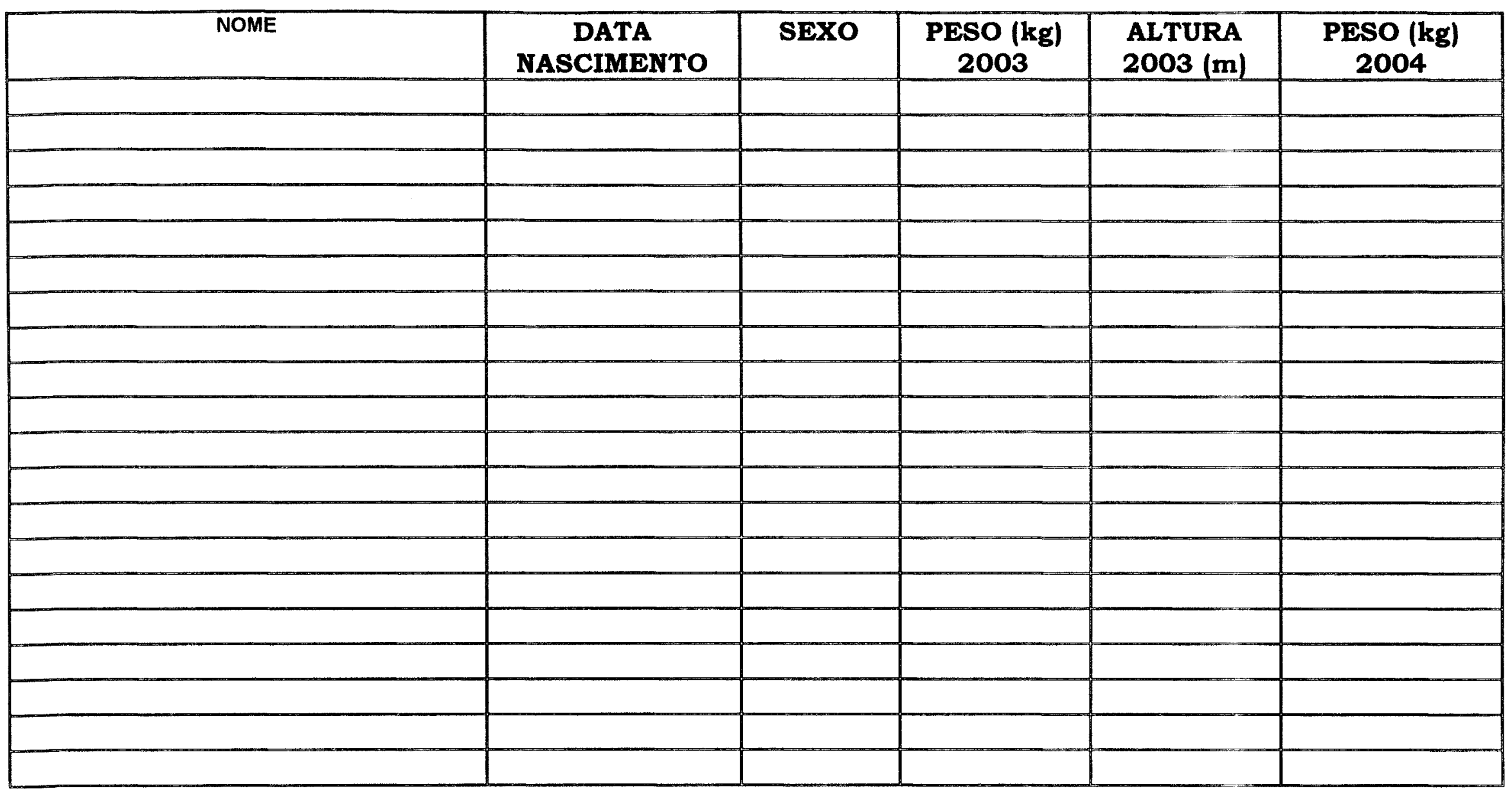




\section{UNTVERIDAdE dE SÃo PAULO Faculdade de Saúde Pública Departamento de Nutrição}

\section{Anexo 3 - Registro Alimentar - Guia Explicativo}

\section{Prezado Aluno}

Com o objetivo de avaliar a sua alimentação você deverá anotar no formulário a seguir, chamado de REGISTRO ALIMENTAR, todos os alimentos (inclusive as bebidas) que você consome no dia, bem como as quantidades. Vocè deverá selecionar 2 dias da semana não consecutivos ( $3^{a}$ e $5^{a}$ feira; $2^{a}$ e $4^{a}$ feira) e mais 1 dia do seu final de semana (ou Sábado ou Domingo) totalizando 3 dias de registro.

Procure utilizar as medidas caseiras para indicar as quantidades de alguns alimentos/preparaçōes que você comeu:

\footnotetext{
$\checkmark$ Açúcar: colher de chá, colher de sobremesa, colher de sopa;

$\checkmark$ Arroz: colher de sopa, colher de servir, escumadeira;

$\checkmark \quad$ Batata: colher de servir, colher de sopa, pires de chá

$\checkmark$ Chocolate em pó: colher de chá, colher de sobremesa, colher de sopa;]

$\checkmark$ Feijāo: concha (pequena, média ou grande)

$\checkmark$ Legumes: colher de sopa, colher de servir, pires de chá;

$\checkmark$ Liquido: xicara de chá, xicara de café, copo de requeijāo

$\checkmark$ Macarrão (ou outras massas): colher de servir, pires de chá, prato raso, prato fundo;

$\checkmark$ Pudim: colher de sopa, colher de servir;

$\checkmark$ Salada (folha): pires de chá, prato raso, prato fundo;

$\checkmark$ Sopa: concha (pequena, média, grande)
}

Ex: 2 colheres de servir de arroz

1 concha média de feijão

1 pires de chá de salada de alface temperada com azeite, sal, limão

Quando possivel, anotar os alimentos em unidade ou medida tradicional. Por exemplo:

(i) Fruta: unidade ou fatia (ex: 1 maçã, 1 fatia de melão, etc)

(3) Pāo: unidade ou fatia (especificar o tipo de pão - ex: francès, de forma, integral etc.)

(-) Queijo: fatia (especificar o tipo, por exemplo: fresco, mussarela, etc)

(-) Bolacha: unidade (especificar qual a bolacha e a marca - ex: chocolate recheada, marca Bauduco);

() Pastel: unidade (indicar sempre o recheio - ex: pastel de feira - tipo pizza);

(3) Esfiha: unidade (indicar se é aberta ou fechada e também o recheio - Ex: de carne, aberta)

(3) Tortas/Bolos: fatia (indicar sempre o recheio e no caso de bolos dizer se tem ou não cobertura - Ex: torta de legumes, bolo de chocolate com recheio de doce de leite e cobertura de chocolate).

()) Sanduiches: sempre especificar os recheios (ex: misto quente -2 fatias de presunto, 2 fatias de queijo tipo mussarela, 1 rodela de tomate).

OBSERVAÇŌES:

(-) Lembre sempre de anotar quando você adoça bebidas (quantidade de açúcar/adoçante);

(-) Sempre que o alimento for industrializado, indicar a marca do mesmo;

(-) Procure anotar os alimentos e suas quantidades da melhor forma, se preferir pode pesá-los, quando possivel:

(-) Anote tudo o que você comer, mesmo se for um bombom ou bala;

(-) Anote tudo o que vocè beber, até mesmo água.

Muito Obrigada pela colaboração!!

Renata Doratioto Albano

(Doutoranda pela FSP/USP e Profa. do curso de Nutriçã). 
UNIVERSIDADE DE SÃO PAULO

Faculdade de Saúde Pública

Departamento de Nutrição

Anexo 4 - REGISTRO ALIMENTAR

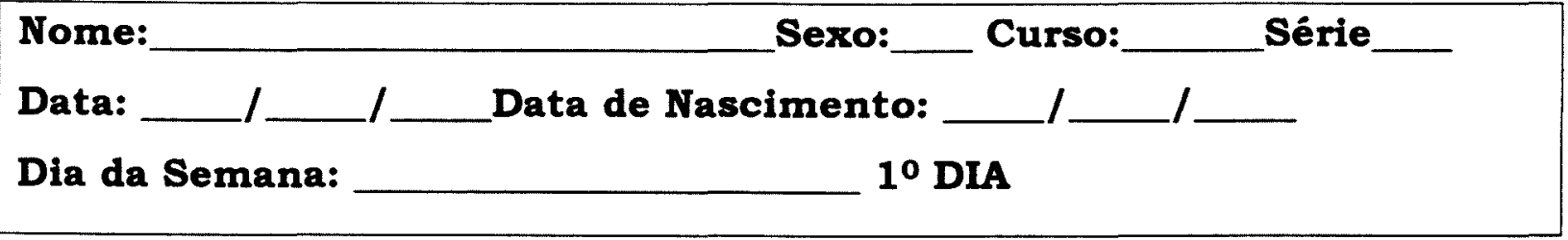

\begin{tabular}{|c|c|c|c|}
\hline HORÁRIO & ALIMENTO/PREPARAÇÃO & QUANTIDADE & MARCA COMERCIAL \\
\hline & & & \\
\hline & & & \\
\hline & & & \\
\hline & & & \\
\hline & & & \\
\hline & & & \\
\hline & & & \\
\hline & & & \\
\hline & & & \\
\hline & & & \\
\hline & & & \\
\hline & & & \\
\hline & & & \\
\hline & & & \\
\hline & & & \\
\hline & & & \\
\hline & & & \\
\hline & & & \\
\hline & & & \\
\hline & & & \\
\hline & & & \\
\hline & & & \\
\hline & & & \\
\hline OBS: & & & \\
\hline
\end{tabular}

Caso necessário, você poderá utilizar o verso da folha 


\section{UNIVERSIDADE DE SÃO PAULO \\ Faculdade de Saúde Pública \\ Departamento de Nutrição}

REGISTRO ALIMENTAR

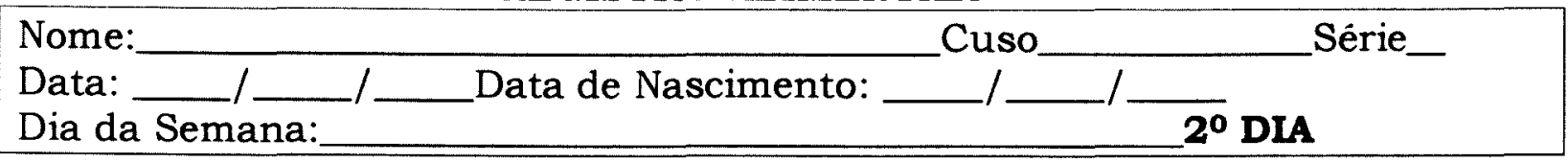

\begin{tabular}{|c|c|c|c|}
\hline HORÁRIO & ALIMENTO/PREPARAÇÃO & QUANTIDADE & MARCA COMERCLAL \\
\hline & & & \\
\hline & & & \\
\hline & & & \\
\hline & & & \\
\hline & & & \\
\hline & & & \\
\hline & & & \\
\hline & & & \\
\hline & & & \\
\hline & & & \\
\hline & & & \\
\hline & & & \\
\hline & & & \\
\hline & & & \\
\hline & & & the \\
\hline & & & - \\
\hline & & & \\
\hline & & & \\
\hline & & & \\
\hline & & & \\
\hline & & & \\
\hline & & & \\
\hline & & & \\
\hline & & & \\
\hline OBS: & & & \\
\hline
\end{tabular}

Caso necessário, você poderá utilizar o verso da folha 


\section{UNIVERSIDADE DE SÃO PAULO}

Faculdade de Saúde Pública

Departamento de Nutrição

\section{REGISTRO ALIMENTAR}

Nome:

Data:

Dia da Semana:

Cuso

Série

Data de Nascimento:

$/-1-\mathbf{3}^{\circ}$ DIA

\begin{tabular}{|c|c|c|c|}
\hline HORÁRIO & ALIMENTO/PREPARAÇÃO & QUANTIDADE & MARCA COMERCLAL \\
\hline & & & \\
\hline & & & \\
\hline & & & \\
\hline & & & \\
\hline & & & \\
\hline & & & \\
\hline & & & \\
\hline & & & \\
\hline & & & \\
\hline & & & \\
\hline & & & \\
\hline & & & \\
\hline & & & \\
\hline & & & \\
\hline & & & \\
\hline & & & \\
\hline & & & \\
\hline & & & \\
\hline & & & \\
\hline & & & \\
\hline & & & \\
\hline & & & \\
\hline & & & \\
\hline & & & \\
\hline & & & \\
\hline OBS: & & & \\
\hline
\end{tabular}

Caso necessário, você poderá utilizar o verso da folha 


\section{Anexo 5 - Aprovação do Projeto de Pesquisa pelo Comitê de Ética}

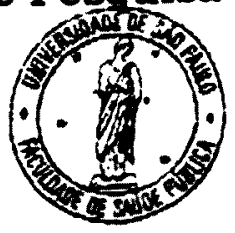

\section{Lniversidade de Sāo Paủo}

Faculdade de Saúde Pública

$$
\text { COMITÉ DE ÉTICA-COEP }
$$

\section{Of.COEP $/ 243 / 02$}

11 e setembro de 2002

Pelo presente, informo que o Comitê de Ética em Pesquisa da Faculdade de Saude Pública da Universidade de Sáo Paulo-COEP, analisou e aprovou, em sua $7^{4}, 02$. realizada em 10.09.02. de acordo com os requisitos da Resolução CNS:19696, o Protocolo de Pesquisa n." 844, intiulado: "ESTADO NUTRICIONAL E CONSUMO ALIMENTAR DE ESTUDANTES DO CLRSO DE NUTRIÇĀO DE UMA NSTITUTCÃO PARTICULAR DE ENSINO SUPERIOR. UM ESTLDO LONGITLDINAI”, apresentado pela pesquisadora Renata Doratioto Albano.

Atenciosamente,

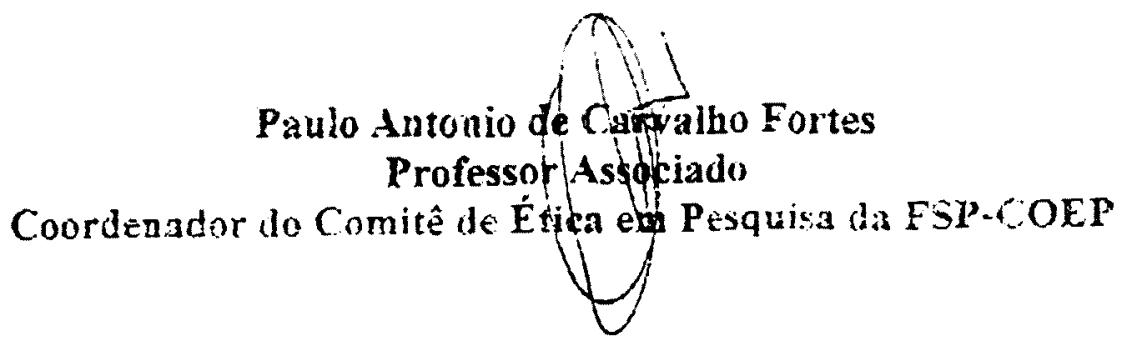


Anexo 6 - Termo De Consentimento Para Participação Na

Pesquisa "ESTADO NUTRICIONAL E CONSUMO ALIMENTAR DE ESTUDANTES DO CURSO DE NUTRIÇÃO DE UMA INSTITUIÇÃO PARTICULAR DE ENSINO SUPERIOR: UM ESTUDO LONGITUDINAL"

(de acordo com a Resolução 196 de 10/10/1996 do Conselho Nacional de Saúde)

Eu,

livremente, quero participar da pesquisa "Estado Nutricional $E$, Consumo Alimentar de Estudantes do Curso de Nutrição de Uma Instituição Particular de Ensino Superior: Um Estudo Longitudinal" sob responsabilidade de Renata Doratioto Albano, Doutoranda em Saúde Pública da Faculdade de Saúde Pública da USP, Orientanda da Professora Dra. Ana Maria D. Gambardella.

Objetivo da Pesquisa: avaliar o estado nutricional e verificar o consumo alimentar de estudantes do curso de Nutrição e do curso de Letras.

Participação: Responder às perguntas necessárias, informar dados sobre o consumo alimentar e permitir que sejam feitas medidas de peso e altura em 2 periodos: março/abril de 2003 e março/abril de 2004.

Riscos: Não haverá riscos para minha integridade fisica, mental ou moral.

Beneficios: As informações obtidas nesta pesquisa poderão ser úteis cientificamente e de ajuda para todos.

Privacidade: Os dados individualizados serão confidenciais. Os resultados coletivos serão divulgados nos meios científicos.

Contatos com os pesquisadores: Terei acesso a telefone para esclarecimento de dúvidas ou reclamações.

Desistência: Poderei desistir a qualquer momento da minha participação, sem qualquer conseqüência para mim.

Assinatura do Aluno 


\section{Anexo 7 - RELATOS COMPLETOS DOS ALUNOS}

VII

\section{Curso de Letras}

"Por ser professora. Gosta de inglês e pretende trabalhar com inglês também e por ser um curso muito enriquecedor".

“Já está na profissão há 15 aos como professora primária”.

"Tem interesse por leitura e acredita que o curso a faça escrever melhor"

"Complementação profissional e afinidade com a área"

"Porque gosta

de leitura”

"Porque fez magistério e pedagogia e quer ter uma licenciatura e letras e é algo que gosta”.

"Bagagem

Cultural"

"Porque gosta de

literatura e inglês"

"Aprimorar os conhecimentos quanto educadora e ampliar os conhecimentos sobre o mundo (história, arte, literatura, etc)"

"Interesse pela língua inglesa e portuguesa" 


\section{Anexo 8 - RELATO COMPLETO DOS ALUNOS Curso de Nutrição}

"Interesse sobre a composição dos alimentos e a contribuição destes p/ a saúde"

'Interesse sobre a composiçâo, crenças e culturas sobre os alimentos. Escolha do curso para aprimorar e poder exercer os conhecimentos sobre nutriçao"

"Conhecer melhor os alimentos e através destes prevenir e recuperar a saúde dos individuos. Ter melhor qualidade de vida"

"Sempre se interessou pelo valor calórico dos alimentos e o que os alimentos fazem no corpo humano"

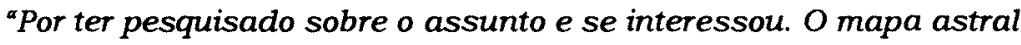
também ajudou"

"Por ser um curso da área da saúde e adora trabalhar com a saúde"

"Primeiro escolheu a area da saúde e depois começou a ler sobre a profissão e se identificou, escolhendo nutriçăo"

"Gosta da área da saúde e das informaçòes sobre alimentação e a relação desta com a qualidade de vida"

"Pois já fez muitas dietas e sabe a dificuldade que é para se conseguir emagrecer e pretende ajudar as pessoas com essa dificuldade"

"Tem interesse na área e gostaria de trabalhar em hospital ou na área de esporte"

"Para poder ter uma alimentação adequada e para ensinar as pessoas sobre issso. Para se ter uma higiene e preparaçao melhor"

"Para melhorar a qualidade de vida das pessoas através da alimentaçao"

"Para melhorar a sua condicao de vida pois se alimenta muito mal foi um curso que a agradou tanto nas matérias como no mercado de trabalho"

"Sempre quis atuar na área da saúde. Adora mexer com os alimentos, saber como sáo feitos e suas funçoes"

"Gosta de sber como os alimentos sáo preparados e saber como nós devemos nos alimentar"

"Ter sido obesa na infancia. Presença de restaurante na familia e surgimento de estudos que relacionam nutriçao e câncer, trazendo uma concepçao de que os alimentos possuuem papel fundamental na vida”

"Sempre se interessou pela alimentação, dietas, receitas. Porque o pai é proprietário de um restaurante"

"Saber sobre a composiçáo dos alimentos e o valor calórico dos alimentos"

"Se interessa pelas calorias, nutrientes, vitaminas e achou interessante se aprofundar no assunto" 